\title{
Accounting Harmonization and Investment Beauty Contests
}

\section{By: Xu Jiang, Chao Tang and Gaoqing Zhang}

\begin{abstract}
We study the optimal degree of harmonization of accounting standards when rms' in-vestments exhibit "beauty-contest" features as in, e.g., Arya and Mittendorf (2016). We model more harmonization of accounting standards as the noises in rms' reports being more correlated, consistent with Barth et al. (1999). We show that while more harmonized accounting standards have ambiguous effects on the reports' informativeness in represent-ing rms' underlying fundamentals, they always reduce the reports' precision in forecasting rms' aggregateinvestment. The stronger the "beauty-contest" features, the more important the forecasts about the aggregate investment, and thus the less harmonized the standards should be. We also nd that, while absent beauty-contest features, mandatory adoption of more harmonized accounting standards can be unnecessary, such mandate is warranted when beauty-contest features are strong. Taken together, our results both provide a justi cation for and identify an unintended consequence of the recent mandates towards more harmonized accounting standards.
\end{abstract}

JEL recognition: M41, M48

Key Words: Beauty Contest, Investment Externality, Information Spillover, Disclosure, Accounting Standards, Harmonization, IFRS Adoption 


\section{Introduction}

We study whether accounting standards should be harmonized when firms' investments exhibit "beauty-contest" externalities. ${ }^{1}$ Our analyses suggest that mandating more harmonized accounting standards has both costs and benefits. We find that, on the one hand, the stronger the beauty-contest externalities, the lower degree of harmonization should be mandated, as imposing a higher degree of harmonization reduces the ability of firms' financial reports in predicting the aggregate firm investments. On the other hand, while higher beauty-contest externalities call for less accounting harmonization, it also provides a justification for the mandatory adoption of (such lower level of) harmonized accounting standards as firms, when left on their own, would adopt even less harmonized standards.

Harmonization of international accounting standards has become more common over the past couple of decades and is an important research topic in accounting (see Baker and Barbu (2007) for a comprehensive review of the accounting standards harmonization literature). For example, there has been extensive adoption of international financial reporting standards (IFRS) since the 1990s (see De George et al. (2016) for an excellent review of the IFRS adoption literature) as well as calls for convergence between US GAAP and IFRS. ${ }^{2}$ Proponents of harmonization of accounting standards tout the benefits of such convergence in terms of improved comparability (Securities and Commission (2008), Tweedie (2008), Wang (2014)), lower processing cost of accounting reports for capital market participants (e.g., DeFond et al. (2011), Covrig et al. (2007), Bradshaw et al. (2004)), and thus positive capital market consequences (e.g., Leuz and Verrecchia (2000), Leuz (2003), Daske et al. (2008), Li (2010)). Opponents of the harmonization, on the other hand, focus on the cost associated with “one-size-fits-all” standards adoption (Brüggemann et al. (2013), Ray (2018)) as well as heterogenous enforcement (Ball et al. (2000), Ball et al. (2003), Leuz et al. (2003), Bushman and Piotroski (2006), Lang et al. (2006), Daske et al. (2013), Christensen et al. (2013), Christensen et al. (2016)).

\footnotetext{
${ }^{1}$ In this paper we use beauty-contest features and investment externalities interchangeably. When investment exhibits beauty-contest features, one firm finds it optimal to invest more (less) if other firms invest more (less). Therefore, firms' investment strategies are complements to each other.

${ }^{2}$ See https://www.fasb.org/jsp/FASB/Page/SectionPage\&cid=1176156304264 for a brief history. See Hail et al. (2010a) and Hail et al. (2010b) for excellent thought pieces on global accounting standards convergence.
} 
However, most, if not all, of the arguments focus exclusively on the costs and benefits on the capital market. While the capital market effect is important to understand the economic consequences of accounting harmonization, two other key factors have been seemingly underexplored in prior studies: 1) the possibility of firms (rather than investors) learning from other firms' reports and 2) the existence of investment externalities among firms. As discussed in Roychowdhury et al. (2019), firms often learn from other firms' disclosures in making investment decisions, and harmonization of accounting standards arguably facilitates such learning. Empirically, Chen et al. (2013) provide supporting evidence that mandatory IFRS adoption has a cross-border spillover effect and improves peer firms' investment efficiency. Perhaps more importantly, investment externalities exhibiting beauty-contest features are pervasive in practice (see detailed discussions in Arya and Mittendorf (2016)) and have become increasingly important as the economies worldwide move towards more service-oriented. For instance, while song producers in the past typically make profits through selling cassettes and CDs, their profits nowadays are driven primarily by the number of listens on streaming platforms such as Spotify. Investment in song production would be more profitable if the songs are streamed through platforms with more audiences. Streaming platforms would also have higher returns from their investments if more popular songs are streamed through their platforms. As another example, it has become increasingly common for companies to run their computing tasks through cloud computing services. Firms' investment in cloud computing would generate higher returns if the cloud computing service they use has more active users, in the sense that their customers/suppliers are more likely to share the same service, thus facilitating interactions and saving costs. Likewise, cloud computing service companies' investments would also be more profitable if more firms invest in cloud computing. In addition, the European Union (EU)'s adoption of IFRS coincides with its attempt of greater economic integration among EU countries. ${ }^{3}$ To the extent that economic integration contributes to investment externalities (Vijil (2014)), the question of whether more or less harmonized accounting standards are desirable in settings with investment externalities appears important and, so far, unexplored in the literature.

\footnotetext{
${ }^{3}$ For more details on this topic, please see, e.g. https://europe.unc.edu/files/2016/11/Brief_EU_Global_Convergence _Accounting_Standards_2007.pdf.
} 
In this paper, we address this question by studying the optimal degree of accounting standards harmonization in a canonical model of investment beauty contests. In our model, there is a continuum of firms making investment decisions. The return of the investment depends not only on each firm's own fundamental but also on how much other firms invest (i.e., the investment externality). Firms' fundamentals are correlated as each has a common component (common fundamental) and an idiosyncratic component (idiosyncratic fundamental). Introducing the common component is a parsimonious way of introducing a correlation in fundamentals across firms. The correlation, in turn, creates a need for firms to learn from other firms' reports. In addition, as in Angeletos and Pavan (2004) and Zhang (Forthcoming), each firm observes private signals about the components of its fundamentals and public signals consisting of accounting reports for itself and all other firms. Accounting reports are modeled as noisy signals of fundamentals and the noise in the reports also consists of a common component (common noise) and an idiosyncratic component (idiosyncratic noise). Following the spirit of Barth et al. (1999) that harmonization makes countries' accounting reports more similar, we model the harmonization of accounting standards as an increase in the common noise while at the same time a decrease in the idiosyncratic noise. Barth et al. (1999) interpret more similar reports as having more common measurement noise, which is consistent with our formulation. We assume there is an accounting standard-setter who chooses the degree of harmonization of accounting standards to maximize social welfare, i.e., the expected payoff for all firms.

We find that in economies with higher investment externalities, harmonization of accounting standards is less desirable, thus pointing to a potential unintended cost of mandating more harmonized accounting standards. To illustrate the intuition, note that it is well-known that in settings of investment beauty contests (e.g., Angeletos and Pavan (2007)) the welfare effect of information depends on how information affects two types of uncertainties: 1) fundamental uncertainty (i.e., the uncertainty regarding the fundamental state) and 2) strategic uncertainty (i.e., the uncertainty regarding others' investment strategies).

We first look at how fundamental uncertainty is affected. We find that more harmonized accounting standards reduce the uncertainty regarding the idiosyncratic fundamental but increase the uncertainty regarding the common fundamental. Intuitively, since the idiosyncratic 
noise and the idiosyncratic fundamental cancels out when averaging across all reports, the mean report is the common fundamental plus the common noise. Similarly, since the common noise and the common fundamental cancels out when subtracting the mean report from each firm's report, each firm's demeaned report equals its idiosyncratic fundamental plus the idiosyncratic noise. More harmonized accounting standards, by increasing the common noise, inject more noise into the mean report and, therefore, amplify the uncertainty regarding the common fundamental. Similarly, by reducing idiosyncratic noise in the demeaned reports, more harmonized accounting standards diminish the uncertainty regarding the idiosyncratic fundamental. Thus, this trade-off generates an interior optimal degree of harmonization even in the absence of the beauty-contest motive.

Second, we find that more harmonized accounting standards always increase strategic uncertainty. To see the intuition, note that strategic uncertainty hinges on uncertainty predicting the average of other firms' investment strategies. Since, in equilibrium, other firms' investment strategies are driven by the fundamentals, and averaging the investments cancels out the idiosyncratic fundamental, the precision of predicting the average of other firms' investments depends only on the degree of uncertainty regarding common fundamental. By increasing the uncertainty regarding common fundamental, more harmonized accounting standards amplify the strategic uncertainty.

In sum, while more harmonized accounting standards have ambiguous effects on the fundamental uncertainty, they always increase the strategic uncertainty. In economies with stronger investment externalities, it is of greater importance to predict other firms' investment strategies, which puts minimizing strategic uncertainty in a more central place. This, in turn, calls for accounting standards to be less harmonized to reduce strategic uncertainty.

We also find that, while higher investment externalities call for a lower level of harmonization, it also justifies the mandatory adoption of (such lower level of) harmonized accounting standards. Specifically, in the absence of investment externalities, firms may voluntarily choose a higher level of harmonization than the choice of a benevolent standard-setter, making mandating more harmonized accounting standards unnecessary. When investment externalities are higher, however, firms always voluntarily choose less harmonized standards than the socially optimal ones. This, in turn, implies the necessity of mandating more har- 
monized accounting standards. The intuition for this result is as follows. In the absence of investment externalities, both the individual firms and the standard-setter are only concerned about predicting the fundamentals. However, while individual firms care only about predicting their own fundamentals, the standard-setter also considers the information spillover effect that one firm's report helps to predict the fundamentals of other firms. In particular, when the precision of signals regarding common fundamentals is low, it is of great importance to generate information about the common fundamental. In response, both the firms and the standard-setter choose to adopt less harmonized accounting standards in order to reduce the uncertainty about the common fundamental. More importantly, the decrease in accounting harmonization comes with an information spillover effect: it helps to reduce the uncertainty about the common fundamental for all firms. However, an individual firm can only internalize the information gain on its own, thus contemplating a smaller private benefit of reducing accounting harmonization than the social benefit. Accordingly, this information spillover induces firms to prefer more harmonized accounting standards than the socially optimal level.

Adding investment externalities, however, alters the preferences of both the individual firms and the standard-setter for accounting harmonization substantially. Because of the beauty-contest feature, both the individual firms and the standard-setter care about aligning the firms' investments with other firms'. Furthermore, the standard-setter cares more about such alignment than the firms. This is because an individual firm is only concerned about setting its own investment close to its peers, whereas the standard-setter cares about aligning the investments among all firms. More harmonized accounting standards help the standard-setter to better align the firms' investments because they make the firms' reports more correlated and thus drive stronger comovements across the firms' investments. As a result, when investment externalities become sufficiently large, the standard-setter would prefer a higher degree of harmonization than what firms would privately choose. Mandating more harmonized accounting standards is thus desirable.

Our paper has the following implications. On the one hand, we caution against adopting more harmonized accounting standards when the degree of investment externalities is too high, as such accounting change introduces correlated reporting noise and amplifies strategic uncertainty. Such an increase of strategic uncertainty is particularly costly in economies 
where the strategic uncertainty is of great importance, i.e., when there are high degrees of investment externalities. To the extent that different countries and industries exhibit different degrees of investment externalities, our results imply that adopting harmonized accounting standards should be decided at an industry-by-industry or country-by-country level. For example, banks and mutual funds are prone to runs and thus may feature greater investment externalities (e.g. Goldstein and Pauzner (2005), Chen et al. (2010)). Therefore, mandating a high degree of harmonization in these industries may not be desirable. Similarly, countries that are subject to excessive capital flights during crises should be cautious in adopting more harmonized accounting standards. Our results thus cast doubt on enhancing accounting standards harmonization as a "desirable single goal" that echoes Barth et al. (1999), even though the underlying mechanism is completely different. While in Barth et al. (1999) the cost of harmonization comes from reducing the reporting precision, in our setting the cost stems from more correlated accounting noise amplifying strategic uncertainty regardless of whether the total precision is increased or decreased.

On the other hand, our paper provides a justification for the recent mandatory harmonization of accounting standards, to the extent that investment externalities have become more and more prominent, as discussed previously. Our paper suggests that it is more desirable to mandate accounting standards harmonization for countries/industries that exhibit higher degree of investment externalities. Nonetheless, the optimal degree of mandated harmonization should still be lower when investment externalities are greater.

\section{$1.1 \quad$ Related literature}

Our paper relates and contributes to several streams of literature. First, it is, to the best of our knowledge, the first paper that studies harmonization of accounting standards in a setting with investment externalities. Closely related to our study, two recent papers by Fang et al. (2019) and Wu and Xue (2019) also examine the optimal degree of harmonization (which they term comparability), yet in different settings with neither investment externalities nor private signals, and they do not study the issue of whether it is desirable to mandate accounting harmonization. In contrast, we consider a setting that features investment externality in the form of an investment beauty contest, which plays a key role in our study of accounting 
harmonization. We find that the presence of investment externalities provides a rationale for mandating accounting harmonization; however, when investment externalities become stronger, the degree of harmonization should still be mandated lower. More broadly, our paper is also related to the literature on accounting standards convergence and, in particular, IFRS adoption. There is a vast empirical literature on this topic but, to the best of our knowledge, only Barth et al. (1999), Gao et al. (2019) and Ray (2018) study this topic analytically. Both Barth et al. (1999) and Gao et al. (2019) are based on trading models that focus on the effect of accounting harmonization on reporting precision as well as on stock market investors' information acquisition effort. Ray (2018), on the other hand, focuses on the trade-off between the investors' lower cost of processing accounting reports and firms' higher compliance costs generated by common accounting standards adoption. Our paper builds on and extends this line of inquiry by examining two other aspects of accounting harmonization that none of the prior studies have examined: 1) how accounting harmonization affects information spillover effects (i.e., accounting harmonization changes the amount and the nature of the information a firm extracts from its peers' reports), and 2) how accounting harmonization shapes the coordination among firms' investments (i.e., firms consider other firms' investment choices when making their own).

Second, our paper is also related to the broad economics literature on coordination as well as its applications in accounting. While the economics literature has pointed out the subtle role information structures play (Angeletos and Pavan (2004), Angeletos and Pavan (2007), Morris and Shin (2002), Myatt and Wallace (2012)), they do not directly speak to how different accounting properties map into those information structures. Subsequently, accounting applications make attempts to provide such mapping and derive accounting implications. For instance, Plantin et al. (2008), Gao and Jiang (2018) and Liang and Zhang (2019) examine the role of accounting measurements in bank runs. Perhaps more related to our study, three other papers in accounting also employ investment beauty-contest models similar to ours, but they study different questions. Arya and Mittendorf (2016) examine how disclosure of firms' private information may be beneficial. Zhang (Forthcoming) studies how competition among firms affects their choices of disclosure precision. Gigler et al. (2016) investigate how mark-to-market accounting in the sense of more precise public information affects a firm's 
ex-ante risk-taking strategy. Note that all three studies focus on examining the effects of improving individual firms' disclosure precision; however, we study the system-wide effect of adopting harmonized accounting standards. Harmonization of accounting standards not only influences the disclosure precision of all firms (albeit the exact effect is ambiguous), but also produces information spillovers across firms, and affects how firms infer others' investments (i.e., strategic uncertainty).

Finally, we also contribute to the literature on disclosure regulation, in particular, the rationalization of mandatory disclosure. Mandatory disclosures are usually justified (or unjustified) on grounds of completely positive (or completely negative) information spillovers (e.g., Fishman and Hagerty (1989), Admati and Pfleiderer (2000), Dye and Sridhar (2008)). See Leuz and Wysocki (2016) for an excellent review). ${ }^{4}$ However, most of the literature focuses on the effect of regulating disclosure precision, and it is a priori unclear how to apply their insights to study the harmonization of accounting standards as more harmonized accounting standards could either increase or decrease precision (Barth et al. (1999) and Gao et al. (2019)). Toward that end, we examine the trade-off regarding mandating accounting harmonization in an investment beauty-contest setting that features both information spillovers and investment externalities. We show that while there may exist a negative externality of mandating more harmonized accounting standards when the beauty-contest feature is weak, the externality becomes positive and makes such mandatory harmonization socially beneficial when the beauty-contest feature is strong. This shift from the negative to the positive externality has, to the best of our knowledge, not been documented before.

The rest of the paper proceeds as follows. Section 2 introduces the model setup. Section 3 analyzes the model. Section 4 provides empirical and regulatory implications and section 5 concludes. The appendix contains all the proofs.

\footnotetext{
${ }^{4}$ An exception is Chen et al. (2017) which also consider a setting with investment externalities but study a different question from ours. In their setting, firms have private information regarding their reporting precision, and accounting regimes can either enable or disable firms to signal their private information.
} 


\begin{tabular}{lll}
\multicolumn{1}{c}{$t=0$} & \multicolumn{1}{c}{$t=1$} & \multicolumn{1}{c}{$t=2$} \\
\hline $\begin{array}{l}\text { Standard-setter chooses the } \\
\text { degree of accounting }\end{array}$ & $\begin{array}{l}\text { Each firm issues accounting } \\
\text { report } r_{i} \text { following accounting } \\
\text { standards harmonization } m .\end{array}$ & $\begin{array}{l}\text { Cash flows from investments } \\
\text { standards, and observes private } \\
\text { signals } s_{i 1} \text { and } s_{i 2} . \text { Firm } \\
\text { chooses investment } k_{i} .\end{array}$
\end{tabular}

Figure 1: Timeline of the model.

\section{The Model}

Our model is built on a canonical model of investment beauty contest widely used in the accounting and economics literature (e.g., Angeletos and Pavan (2004), Angeletos and Pavan (2007), Arya and Mittendorf (2016), Chen et al. (2017)), augmented with our formulation of harmonized accounting standards. The model has three dates, $t \in\{0,1,2\}$, and includes an accounting standard-setter and a continuum of firms over the unit interval $[0,1]$, indexed by $i$. Figure 1 summarizes the timeline of our model.

Specifically, at date 0, each firm $i$ is endowed with an investment opportunity, the return of which will be realized at date 2 and depends on the firm's fundamental:

$$
\theta_{i}=\theta+\lambda_{i}
$$

where $\theta \sim N\left(\mu_{\theta}, \frac{1}{h_{\theta}}\right)$ and $\lambda_{i} \sim N\left(0, \frac{1}{h_{\lambda}}\right)$ is independent of $\theta$. Each firm's fundamental, therefore, consists of two components, a common component $\theta$ and an idiosyncratic component $\lambda_{i}$. For ease of exposition, we call these two components as the common fundamental and idiosyncratic fundamental hereafter.

At date 1 , each firm $i$ prepares and issues an accounting report $r_{i}$, the process of which is governed by some accounting standards set by the standard-setter. We will specify how the accounting standards are set in more detail later. In addition, each firm $i$ also privately observes two independent signals. One signal reveals the common fundamental $\theta$ with noise and the other reveals the idiosyncratic fundamental $\lambda_{i}$ with noise, that is,

$$
s_{i 1}=\theta+\xi_{i 1} ; s_{i 2}=\lambda_{i}+\xi_{i 2},
$$


where $\xi_{i 1} \sim N\left(0, \frac{1}{h_{\xi_{1}}}\right), \xi_{i 2} \sim N\left(0, \frac{1}{h_{\xi_{2}}}\right)$ and the noises are independent both within and across firms. Following the investment beauty-contest literature, we assume that the private signals are "soft information" known by the firms and cannot be credibly communicated to outsiders.

Upon observing the accounting reports of all firms and its own private signals, firm $i$ chooses to invest $k_{i}$ at a cost of $\frac{k_{i}^{2}}{2}$ at date 1. Importantly, following Angeletos and Pavan (2004) and Arya and Mittendorf (2016), we assume that the return to each firm $i$ 's investment exhibits a beauty-contest feature as follows:

$$
R_{i}=(1-\alpha) \theta_{i}+\alpha K
$$

where $\alpha \in[0,1)$ and $K$ is the aggregate investment in the economy, i.e., $K \equiv \int_{0}^{1} k_{i} d i$. Equation (1) implies that firm $i$ earns a higher investment return and hence has a stronger incentive to invest either when the firm receives a favorable shock to its fundamental (higher $\theta_{i}$ ), or when other firms also make larger investments (higher $K$ ). The parameter $\alpha$ thus captures the magnitude of the beauty-contest feature or the level of investment externalities. As discussed in the introduction, the beauty-contest feature is quite common in practice, and equation (1) provides a parsimonious reduced-form representation of this feature. In addition, we also develop an economic setting in Appendix II that micro-founds (1) and derives the equation endogenously as a result of optimal trades among firms.

In sum, each firm $i$ chooses $k_{i}$ to maximize the following expected payoff conditional on its information set:

$$
\max _{k_{i}} V_{i} \equiv E\left[R_{i} k_{i}-\frac{k_{i}^{2}}{2} \mid r_{i}, r_{-i}, s_{i 1}, s_{i 2}\right]
$$

where $r_{-i}$ denotes all firms' accounting reports other than firm $i$ 's. Therefore, the information set for firm $i$ at date 1 before choosing $k_{i}$ includes $\left\{r_{i}, r_{-i}, s_{i 1}, s_{i 2}\right\}$, i.e., all the public accounting reports and firm $i$ 's private signals. To economize on notation, we often omit stating the firm's information set and simply write each firm's conditional expectation given its information set as $E_{i}[\cdot]$, whenever no confusion arises.

So far, our model is a standard investment beauty-contest model. We now augment it 
by formulating how harmonization of accounting standards governs the firms' accounting reports. Specifically, we assume that the accounting report for firm $i$ is

$$
r_{i}=\theta_{i}+m \eta+(1-m) \varepsilon_{i},
$$

where $m \in(0,1)$ and higher $m$ represents more harmonized accounting standards. Equation (3) indicates that the accounting report of firm $i$ is a noisy signal of firm $i$ 's fundamental. The reporting noise also consists of two independent components: a common reporting noise $\eta \sim N\left(0, \frac{1}{h_{\eta}}\right)$ and an idiosyncratic reporting noise $\varepsilon_{i} \sim N\left(0, \frac{1}{h_{\varepsilon}}\right)$, which is i.i.d. across firms. Therefore, more harmonized accounting standards increase common noise and, at the same time, decrease idiosyncratic noise in accounting reports.

Our notion of higher $m$ representing more harmonized accounting standards is consistent with that in Barth et al. (1999). ${ }^{5}$ To see this, note that in Barth et al. (1999) more harmonized accounting standards are operationalized as reducing the variance of the difference between the measurement noise when using a country's own accounting standards and the measurement noise when using another country's accounting standards. Correspondingly, in our setting, consider two firms/countries indexed by $i$ and $j$. Using firm/country $i$ 's own accounting standards results in the measurement noise being $m \eta+(1-m) \varepsilon_{i}$ and using firm/country $j$ 's accounting standards results in the measurement noise being $m \eta+(1-m) \varepsilon_{j}$, where $\varepsilon_{j}$ represents the idiosyncratic reporting noise of using firm/country $j$ 's accounting standard, which, by assumption, is independent and identically distributed with $\varepsilon_{i}$. The difference of their measurement error is thus $m \eta+(1-m) \varepsilon_{i}-\left(m \eta+(1-m) \varepsilon_{j}\right)=(1-m)\left(\varepsilon_{i}-\varepsilon_{j}\right)$, and the variance is

$$
\operatorname{Var}\left(m \eta+(1-m) \varepsilon_{i}-\left(m \eta+(1-m) \varepsilon_{j}\right)\right)=(1-m)^{2} \frac{2}{h_{\varepsilon}}
$$

which is strictly decreasing in $m$. In other words, when $m$ increases, the measurement noise difference between any two countries' accounting reports decline. In particular, when

\footnotetext{
${ }^{5}$ Prior papers (e.g., Fang et al. (2019)) have also used the relative magnitude of common noises in accounting reports to model accounting comparability. Our modeling of accounting standard harmonization is in line with the spirits of those papers, to the extent that more harmonization of accounting standards improves the comparability among accounting reports.
} 
$m=1$, the variance reaches zero, suggesting that the standards between firm/country $i$ and firm/country $j$ are "completely harmonized."

We assume that a benevolent standard-setter chooses the degree of accounting standards harmonization $m$ at date 0 to maximize the ex-ante social welfare, defined as the expected payoff among all firms, i.e.,

$$
W \equiv E\left[\int_{0}^{1} V_{i} d i\right]
$$

The table below summarizes the notations of the paper.

\begin{tabular}{llll}
\hline Notation & Variable & Notation & Variable \\
\hline \hline$\theta_{i}$ & firm $i$ 's fundamental & $\theta$ & common fundamental \\
$\mu$ & mean of $\theta$ & $\lambda_{i}$ & firm $i$ 's idiosyncratic fundamental \\
$r_{i}$ & public accounting report of firm $i$ & $\eta$ & common reporting noise \\
$\varepsilon_{i}$ & firm $i$ 's idiosyncratic reporting noise & $m$ & accounting standards harmonization \\
$s_{i 1}$ & firm $i$ 's private signal about $\theta$ & $\xi_{i 1}$ & noise of the signal $s_{i 1}$ \\
$s_{i 2}$ & firm $i$ 's private signal about $\lambda_{i}$ & $\xi_{i 2}$ & noise of the signal $s_{i 2}$ \\
$h_{\theta}$ & precision of $\theta$ & $h_{\lambda}$ & precision of $\lambda_{i}$ \\
$h_{\eta}$ & precision of $\eta$ & $h_{\varepsilon}$ & precision of $\varepsilon_{i}$ \\
$h_{\xi_{1}}$ & precision of $\xi_{i 1}$ & $h_{\xi_{2}}$ & precision of $\xi_{i 2}$ \\
$k_{i}$ & firm $i$ 's investment & $K$ & aggregate investment \\
$R_{i}$ & firm $i$ 's return to investment & $\alpha$ & degree of the beauty-contest motive \\
$V_{i}$ & firm $i$ 's expected payoff given information & $W$ & social welfare \\
\hline
\end{tabular}

Table 1: Notations.

\section{Analysis}

\subsection{Informational properties of harmonized accounting standards}

As a preliminary step, we analyze how harmonization of accounting standards affects the information content of accounting reports as such analysis will be crucial to understand 
the economic consequences of accounting harmonization. In an investment beauty-contest model, the provision of information serves two purposes. It helps each firm to better assess the state of fundamentals (i.e., reducing fundamental uncertainty), and the beliefs held by the other firms (i.e., reducing strategic uncertainty). In this section, we provide insights into how harmonization of accounting standards affects the two types of uncertainty. In doing so, we first decompose the set of correlated accounting reports $\left\{r_{i}\right\}_{i \in[0,1]}$ into two sets of orthogonal signals, each of which is a sufficient statistic for the common and the idiosyncratic fundamental, respectively. The first signal is the average accounting report:

$$
\bar{r}=\int_{0}^{1}\left(\theta_{i}+m \eta+(1-m) \varepsilon_{i}\right) d i=\theta+m \eta
$$

Note that $\bar{r}$ is a signal of the common fundamental $\theta$ only, as all of the idiosyncratic components are averaged out. Conditional on $\bar{r}$, a firm's accounting report $r_{i}$ does not provide any incremental information about $\theta$. The other signal is the demeaned report:

$$
v_{i}=r_{i}-\bar{r}=\lambda_{i}+(1-m) \varepsilon_{i},
$$

i.e., the difference between a firm's accounting report $r_{i}$ and the average report $\bar{r}$. Note that $v_{i}$ is a signal of the idiosyncratic fundamental $\lambda_{i}$ only, as the common components are canceled out. Conditional on $v_{i}$, the accounting report $r_{i}$ does not provide any incremental information about $\lambda_{i}$. These results are formally stated in the following lemma.

Lemma 1 The set of accounting reports $\left\{r_{i}\right\}_{i \in[0,1]}$ can be decomposed as follows:

1. The average report $\bar{r}=\theta+m \eta$ is a sufficient statistic for $\theta$;

2. The demeaned report $v_{i}=\lambda_{i}+(1-m) \varepsilon_{i}$ is a sufficient statistic for $\lambda_{i}$.

Having characterized the sufficient-statistic results, we now turn to examining how harmonization of accounting standards affects the fundamental and the strategic uncertainty through changing the information content of the average and the demeaned reports. We first formally define the fundamental uncertainty. Recall that there are two fundamental components, the common fundamental $\theta$ and the idiosyncratic fundamental $\lambda_{i}$. Naturally, 
the uncertainty regarding $\theta$ and $\lambda_{i}$, conditional on a firm $i$ 's information set $\left\{r_{i}, r_{-i}, s_{i 1}, s_{i 2}\right\}$, is measured by the conditional variances, $\operatorname{Var}\left(\theta \mid r_{i}, r_{-i}, s_{i 1}, s_{i 2}\right)$ and $\operatorname{Var}\left(\lambda_{i} \mid r_{i}, r_{-i}, s_{i 1}, s_{i 2}\right)$, respectively. To economize on notation, we often omit firm $i$ 's information set and write the conditional variance as $\operatorname{Var}_{i}(\cdot)$. The following proposition then characterizes the role of accounting standards harmonization $m$ in affecting $\operatorname{Var}_{i}(\theta)$ and $\operatorname{Var}_{i}\left(\lambda_{i}\right)$.

Proposition 1 When accounting standards become more harmonized,

- fundamental uncertainty regarding $\lambda_{i}$ is lower, i.e., $\frac{\partial \operatorname{Var}_{i}\left(\lambda_{i}\right)}{\partial m}<0$;

- fundamental uncertainty regarding $\theta$ is higher, i.e., $\frac{\partial \operatorname{Var}_{i}(\theta)}{\partial m}>0$.

Proposition 1 follows directly from Lemma 1. Lemma 1 states that the average report is common fundamental plus common noise whereas the demeaned report is idiosyncratic fundamental plus idiosyncratic noise. Therefore, more harmonized accounting standards would amplify the uncertainty about the common fundamental as it adds common noise into the average report. In contrast, by reducing idiosyncratic noise in the demeaned reports, more harmonized accounting standards diminish the uncertainty regarding the idiosyncratic fundamental.

Next, we examine the effect of accounting standards harmonization on strategic uncertainty. Following the investment beauty-contest literature (e.g., Angeletos and Pavan (2004)), strategic uncertainty measures how well firm $i$ is able to forecast other firms' beliefs. Formally, from firm $i$ 's perspective, the belief of a firm $j \neq i$ about its fundamental $\theta_{j}$ is given by $E_{j}\left[\theta_{j}\right]$. Therefore, on average, all other firms' beliefs about their fundamentals are given by:

$$
\bar{E}\left[\theta_{j}\right]=\int_{0}^{1} E_{j}\left[\theta_{j}\right] d j,
$$

where $\bar{E}[\cdot]$ denotes the average beliefs of all firms. Now consider how well firm $i$ 's information helps it to predict the average of other firms' beliefs about their own fundamentals, i.e., $\bar{E}\left[\theta_{j}\right]$. The relevant measure here is the conditional variance of estimating $\bar{E}\left[\theta_{j}\right]$ given firm $i$ 's information, i.e., $\operatorname{Var}_{i}\left(\bar{E}\left[\theta_{j}\right]\right)$. The following proposition characterizes the effect of accounting standards harmonization $m$ on $\operatorname{Var}_{i}\left(\bar{E}\left[\theta_{j}\right]\right)$. 
Proposition 2 Strategic uncertainty strictly increases in accounting standards harmonization, i.e., $\frac{\partial \operatorname{Var}_{i}\left(\bar{E}\left[\theta_{j}\right]\right)}{\partial m}>0$.

Proposition 2 suggests that while more harmonized accounting standards have ambiguous effects on the precision of forecasting the common and the idiosyncratic fundamentals, they always make the forecast of others' beliefs more difficult, i.e., the strategic uncertainty increases. To see the intuition, note that when firm $i$ forecasts the average of other firms' beliefs about their own fundamentals, it only needs to forecast other firms' beliefs about the common fundamental $\theta$, as their beliefs about the idiosyncratic fundamental $\lambda_{j}$ are averaged out. Since more harmonized accounting standards increase the fundamental uncertainty regarding $\theta$, they also make it more difficult for each firm to forecast others' beliefs about the fundamentals. As a result, strategic uncertainty heightens as accounting standards become more harmonized.

\subsection{Economic consequences of harmonized accounting standards}

\subsubsection{No beauty-contest benchmark}

To help illustrate the interaction between investment externality and harmonized accounting standards in our setting, it is instructive to first examine a benchmark in which there is no investment externality, i.e., $\alpha=0$. Taking the first-order condition of the firm's payoff function (2) with respect to $k_{i}$ yields the following decision rule:

$$
k_{i}=E_{i}\left[\theta_{i}\right]
$$

Plugging (7) into (2) gives the firm's expected payoff:

$$
V_{i}=\frac{\left[E_{i}\left[\theta_{i}\right]\right]^{2}}{2}=\frac{E_{i}\left[\theta_{i}^{2}\right]-\operatorname{Var}_{i}\left(\theta_{i}\right)}{2}
$$


Integrating $V_{i}$ over the population of firms, we obtain social welfare, defined in (4), as: ${ }^{6}$

$$
W=\frac{\left[E\left[\theta_{i}\right]\right]^{2}+\operatorname{Var}\left(\theta_{i}\right)-\operatorname{Var}_{i}\left(\theta_{i}\right)}{2} \propto-\operatorname{Var}_{i}\left(\theta_{i}\right)=-\operatorname{Var}\left(\theta \mid \bar{r}, s_{i 1}\right)-\operatorname{Var}\left(\lambda_{i} \mid v_{i}, s_{i 2}\right),
$$

where " $\propto$ " means "strictly increasing in." Intuitively, equation (8) suggests that maximizing social welfare is equivalent to minimizing the uncertainty about the common fundamental $\theta$ and the idiosyncratic fundamental $\lambda_{i}$. This is intuitive, because absent investment externality, optimal decision-making only requires the most precise assessments of fundamentals. The following proposition states that there exists an interior and unique level of accounting standards harmonization that minimizes the fundamental uncertainty.

Proposition 3 When there is no investment externality, i.e., $\alpha=0$, there always exists an interior and unique level of accounting standards harmonization $m_{0}^{*}$ that maximizes social welfare.

Proposition 3 suggests that it is never optimal to adopt accounting standards that are fully harmonized or completely idiosyncratic. This is because making accounting standards more harmonized generates a benefit and a cost: it alleviates the uncertainty regarding the idiosyncratic fundamental at the expense of elevating the uncertainty regarding the common fundamental. When one type of uncertainty is at extremely high levels (i.e. the other type is at extremely low levels), the benefit of reducing the extremely high uncertainty outweighs the cost of increasing the extremely low uncertainty. Balancing the benefit and cost thus requires implementing an interior level of accounting standards harmonization, rather than extreme levels.

\footnotetext{
${ }^{6}$ Formally, the first step in the derivation of $W$ uses the law of iterated expectations, i.e., $E\left[\int_{0}^{1} E_{i}\left[\theta_{i}^{2}\right] d i\right]=$ $E\left[\theta_{i}^{2}\right]=\left[E\left[\theta_{i}\right]\right]^{2}+\operatorname{Var}\left(\theta_{i}\right)$, and $\operatorname{Var}_{i}\left(\theta_{i}\right)$ is the same across all firms. The second step exploits the fact that $\left[E\left[\theta_{i}\right]\right]^{2}+\operatorname{Var}\left(\theta_{i}\right)=\mu_{\theta}^{2}+\frac{1}{h_{\theta}}+\frac{1}{h_{\lambda}}$ is a constant and thus can be dropped in the optimization program. The third step comes from Lemma 1, i.e., the average report $\bar{r}$ is a sufficient statistic for $\theta$ whereas the demeaned report $v_{i}$ is a sufficient statistic for $\lambda_{i}$.
} 


\subsubsection{Full model with beauty contest}

We now turn to the full model with investment externalities. Taking the first-order condition of the firm's payoff function (2) with respect to $k_{i}$ gives the firm's optimal investment rule:

$$
k_{i}=E_{i}\left[R_{i}\right]=(1-\alpha) E_{i}\left[\theta_{i}\right]+\alpha E_{i}[K] .
$$

Equation (9) suggests that, with investment externality $(\alpha>0)$, each firm chooses its investment to match not only its own fundamentals but also the other firms' investments $K$. The latter motive makes forecasting $K$ (i.e., strategic uncertainty) a key consideration for each firm. Following Angeletos and Pavan (2004), the equilibrium investment can be solved via a "guess-and-verify" approach, which we briefly outline here. Conjecture that the firm's investment $k_{i}$ is linear in all the signals in the firm's information set $\left\{\bar{r}, v_{i}, s_{i 1}, s_{i 2}\right\}$ :

$$
k_{i}=\psi_{0}+\psi_{\bar{r}} \bar{r}+\psi_{v} v_{i}+\psi_{s_{1}} s_{i 1}+\psi_{s_{2}} s_{i 2},
$$

where the coefficients $\left\{\psi_{0}, \psi_{\bar{r}}, \psi_{v}, \psi_{s_{1}}, \psi_{s_{2}}\right\}$ will be endogenously determined in equilibrium. Then, the aggregate investment is

$$
K=\int_{0}^{1} k_{i} d i=\psi_{0}+\psi_{\bar{r}} \bar{r}+\psi_{s_{1}} \theta
$$

Note that the idiosyncratic fundamentals and the idiosyncratic noise are canceled out in the aggregation. Plugging the conjectures of $\left\{k_{i}, K\right\}$ into (9) and matching the coefficients gives the equilibrium level of investments, which we state formally in the following proposition.

Proposition 4 When $\alpha>0$, i.e., there is investment externality,

1. in equilibrium, each firm chooses an investment

$$
k_{i}=\frac{h_{\theta} \mu_{\theta}+\frac{h_{\eta}}{m^{2}} \bar{r}+(1-\alpha) h_{\xi_{1}} s_{i 1}}{h_{\theta}+\frac{h_{\eta}}{m^{2}}+(1-\alpha) h_{\xi_{1}}}+(1-\alpha) \frac{\frac{h_{\varepsilon}}{(1-m)^{2}} v_{i}+h_{\xi_{2}} s_{i 2}}{h_{\lambda}+\frac{h_{\varepsilon}}{(1-m)^{2}}+h_{\xi_{2}}},
$$


and the aggregate investment is given by

$$
K=\frac{h_{\theta} \mu_{\theta}+\frac{h_{\eta}}{m^{2}} \bar{r}+(1-\alpha) h_{\xi_{1}} \theta}{h_{\theta}+\frac{h_{\eta}}{m^{2}}+(1-\alpha) h_{\xi_{1}}} .
$$

2. Compared with the no-beauty-contest benchmark $(\alpha=0)$, with respect to the common fundamental $\theta$, each firm overweights the average report $\bar{r}$ and underweights the private signal $s_{i 1}$, whereas, with respect to the idiosyncratic fundamental $\lambda_{i}$, the firm does not overweight nor underweight any signal of the pair $\left\{v_{i}, s_{i 2}\right\}$.

Part 1 of Proposition 4 confirms our conjecture of the linear equilibrium. ${ }^{7}$ The equilibrium investment is the sum of the weighted average of the firm's signals about the common fundamental $\theta$, i.e., the public average report $\bar{r}$ and the private signal $s_{i 1}$, and the weighted average of the signals about the idiosyncratic fundamental $\lambda_{i}$, i.e., the public demeaned report $v_{i}$ and the private signal $s_{i 2}$.

Part 2 of the proposition sheds light on how the firm places weight between the public and the private signals. Prior literature suggests that, in investment beauty-contest settings, players tend to place higher (lower) weight on public (private) signals, relative to the weight under Bayesian updating (e.g., Morris and Shin (2002), Angeletos and Pavan (2004)). This is because public signals have additional informational value in forecasting the behavior of other players. Part 2 of Proposition 4 indicates that the average report $\bar{r}$ is indeed overweighted; however, the demeaned report $v_{i}$, albeit public, receives the non-distorted Bayesian weight. The intuition for this result is straightforward. Firm $i$ 's fundamental $\theta_{i}$ affects firm $i$ 's return to the investment and thus its equilibrium investment $k_{i}$. Aggregating $k_{i}$ averages out the idiosyncratic component of $\theta_{i}$, i.e., only the common fundamental $\theta$ matters in the aggregate investment $K$ (as in (12)). As a result, only the public signal $\bar{r}$, which is informative about $\theta$, has the additional informational value in forecasting $K$, and is thus overweighted. By contrast, since neither of the signals about $\lambda_{i}$, public or private, is useful in forecasting $K$, the weights on those signals are still the Bayesian weights. In light of this, Proposition 4 extends the standard overweighting-public-information results derived in settings with

\footnotetext{
${ }^{7}$ Following the approach in Angeletos and Pavan (2004) to express investment as functions of higher-order beliefs, we can show that the linear equilibrium in Proposition 3 is also the unique equilibrium if $\alpha \in[0,1)$.
} 
homogenous fundamentals to settings with heterogenous fundamentals, and suggests that public information is overweighted only when it is informative about the common component of fundamentals.

An observation of the equilibrium investment (equation (11)) also suggests that the level of accounting harmonization $m$ plays a key role in determining the weights on the signals. To generate further implications, the following corollary provides some comparative statics regarding how the weights change with $m$.

Corollary 1 The level of accounting harmonization $m$ affects the weights $\left\{\psi_{\bar{r}}, \psi_{s_{1}}, \psi_{v}, \psi_{s_{2}}\right\}$ in the firm's investment as follows:

1. With respect to the common fundamental,

(a) the weight on the average report, $\psi_{\bar{r}}$, decreases in $m$,

(b) the weight on the private signal, $\psi_{s_{1}}$, increases in $m$,

(c) the total weight, $\psi_{\bar{r}}+\psi_{s_{1}}$, decreases in $m$;

2. With respect to the idiosyncratic fundamental,

(a) the weight on the demeaned report, $\psi_{v}$, increases in $m$,

(b) the weight on the private signal, $\psi_{s 2}$, decreases in $m$,

(c) the total weight, $\psi_{v}+\psi_{s_{2}}$, increases in $m$.

Part 1 of Corollary 1 suggests that, more harmonized accounting standards induce each firm to rely less on the average report and, correspondingly, more on the private signal $s_{i 1}$, in determining the firm's investment. This is intuitive as accounting standards harmonization makes the average report less informative about the common fundamental, and as a result, each firm lowers the weight on the average report and increases the weight on the corresponding private signal. Furthermore, the total weight on the signals about the common fundamental is decreasing in $m$. This is because, as the average report becomes less precise, the firm also increases the weight on the prior, thus reducing the overall weight on the signals. Analogously, part 2 of Corollary 1 sheds light on how accounting standards harmonization 
affects the weights on the signals about the idiosyncratic fundamental. Intuitively, the effect of accounting standards harmonization is exactly the opposite to that of the common fundamental, as more harmonized accounting standards increase, rather than decrease, the precision of the demeaned report about the idiosyncratic fundamental.

Having characterized the equilibrium investment, we now examine our main research question, that is, whether accounting standards should be more or less harmonized when firms' investments exhibit beauty-contest features. Answering this question requires us to compare the optimal level of accounting standards harmonization in the no-beauty-contest benchmark, $m_{0}^{*}$, with that in the model with beauty-contest features, $m^{*}$. However, due to the complexity of our information structure, neither $m_{0}^{*}$ nor $m^{*}$ has a closed-form solution. Thus in general, we are unable to compare them directly. To facilitate this comparison, we need to impose an assumption to guarantee the concavity of social welfare in the level of accounting harmonization such that there exists a unique global maximum in social welfare. As it turns out, a sufficient condition for the concavity is that the accounting reports are sufficiently precise:

Assumption $1 h_{\eta}>3\left(h_{\theta}+h_{\xi_{1}}\right)$ and $h_{\varepsilon}>3\left(h_{\lambda}+h_{\xi_{2}}\right) .8$

We now state the result comparing $m_{0}^{*}$ and $m^{*}$ in the following proposition.

Proposition 5 There exists a uniquely optimal degree of accounting standards harmonization $m^{*}$ in the full model with the beauty-contest feature. Compared with the optimal degree of harmonization in the no-beauty-contest benchmark $m_{0}^{*}, m^{*}$ is always lower and strictly decreasing in the investment externality $\alpha$, i.e., $m^{*}<m_{0}^{*}$ and $\frac{\partial m^{*}}{\partial \alpha}<0$.

Proposition 5 summarizes the main message of our paper. It shows that, in the presence of the beauty-contest feature, the optimal accounting standards should be made less harmonized, compared with the benchmark in which such beauty-contest feature is absent. Furthermore, the stronger the beauty-contest features, the less harmonized the optimal accounting standards. To illustrate the intuition, we first rewrite social welfare in our model as

\footnotetext{
${ }^{8}$ Numerical analysis suggests that Assumption 1 is only sufficient but unnecessary for our comparison results. Therefore the results can still hold even outside the parameter restriction of Assumption 1.
} 
follows: ${ }^{9}$

$$
\begin{gathered}
W \propto \quad(1-\alpha)^{2} \times \underbrace{\left[-\operatorname{Var}_{i}\left(\theta_{i}\right)\right]}_{\text {benchmark }}+\alpha^{2} \times \underbrace{\left[\operatorname{Var}(K)-\operatorname{Var}_{i}(K)\right]}_{\text {amplifying strategic uncertainty }} \\
+2 \alpha(1-\alpha) \times \underbrace{\left[\operatorname{Cov}(\theta, K)-\operatorname{Cov}_{i}(\theta, K)\right]}_{\text {attenuating response to fundamentals }}
\end{gathered}
$$

Compared with social welfare in the no-beauty-contest benchmark (8), there are two additional terms, as shown in (13). We find that both terms are strictly decreasing in the degree of harmonization $m$, and hence represent two additional endogenous costs of accounting harmonization when firms' investments exhibit beauty-contest features. Because of the two additional costs, the optimal degree of harmonization in the case with the beauty-contest feature should be lower than that when the feature is absent. We now explain the two costs in detail.

The second term in (13) measures the difference between firm $i$ 's prior and posterior (strategic) uncertainty about the other firms' investments $K$, and thus reflects the amount of reduction in firm $i$ 's uncertainty about $K$ due to the arrival of information (i.e., accounting reports and private signals). This term suggests that, compared with the no-beauty-contest benchmark in which social welfare can only be improved by reducing fundamental uncertainty (i.e., $\operatorname{Var}_{i}\left(\theta_{i}\right)$ ), reducing strategic uncertainty also improves the welfare when there are investment externalities. Recall from Proposition 2 that more harmonized accounting standards amplify the strategic uncertainty faced by the firms and makes it more difficult to forecast $K$. Therefore, the second term decreases as accounting harmonization impairs the informativeness of accounting reports about $K$, i.e., making $\operatorname{Var}_{i}(K)$ closer to $\operatorname{Var}(K)$.

The last term in (13) measures the difference between the prior and the posterior covariances between the common fundamental $\theta$ and the firms' investments $K$, and its magnitude

\footnotetext{
${ }^{9}$ Formally, we first plug the firm's investment (9) into the firm's payoff $V_{i}$, as defined in (2), and integrating $V_{i}$ over the population of firms. This yields

$$
W=\frac{(1-\alpha)^{2}}{2} E\left[\left(E_{i}\left[\theta_{i}\right]\right)^{2}\right]+\frac{\alpha^{2}}{2} E\left[\left(E_{i}[K]\right)^{2}\right]+\alpha(1-\alpha) E\left[E_{i}\left[\theta_{i}\right] E_{i}[K]\right]
$$

Next, applying the law of iterated expectations gives that $E\left[\left(E_{i}\left[\theta_{i}\right]\right)^{2}\right]=\left[E\left[\theta_{i}\right]\right]^{2}+\operatorname{Var}^{2}\left(\theta_{i}\right)-\operatorname{Var}_{i}(\theta)$ and $E\left[\left(E_{i}[K]\right)^{2}\right]=[E[K]]^{2}+\operatorname{Var}[K]-\operatorname{Var}_{i}(K)$. In addition, applying the law of total covariances results in $E\left[E_{i}\left[\theta_{i}\right] E_{i}[K]\right]=\mu_{\theta}^{2}+\operatorname{cov}\left(E_{i}[\theta], E_{i}[K]\right)=\mu_{\theta}^{2}+\operatorname{Cov}(\theta, K)-\operatorname{Cov}_{i}(\theta, K)$. Note that ex ante, $\left[E\left[\theta_{i}\right]\right]^{2}+$ $\operatorname{Var}\left(\theta_{i}\right)=\mu_{\theta}^{2}+\frac{1}{h_{\theta}}+\frac{1}{h_{\lambda}}$ and $[E[K]]^{2}=\mu_{\theta}^{2}$ are all constants. Dropping the constants yields (13).
} 
depends on the extent to which the provision of information, ex-ante, strengthens the responsiveness of $K$ to $\theta$. Higher responsiveness of $K$ to $\theta$ improves social welfare because, from Proposition 4, the investment $K$ is less responsive to $\theta$ than the socially optimal level (i.e., inertia), due to the excessive weight placed on the public prior about $\theta$. In light of this, an increase in this responsiveness mitigates such inefficient inertia and improves welfare.

We now explain how more harmonized accounting standards affect the responsiveness of $K$ to $\theta$. Note first that, from equation (12), the responsiveness of $K$ to $\theta$ is given by the total weight on the signals about the common fundamental $\left\{\bar{r}, s_{i 1}\right\}$. Corollary 1 suggests that more harmonized accounting standards decrease the total weight on $\left\{\bar{r}, s_{i 1}\right\}, \psi_{\bar{r}}+\psi_{s_{1}}$, thus decreasing the responsiveness of $K$ to $\theta$ and impairing welfare.

In sum, analyzing the welfare expression (13) highlights two additional costs of making accounting standards more harmonized in environments with investment externalities: more harmonized accounting standards reduce firms' ability to predict others' actions, and coordinate firms to respond less promptly to shocks in fundamentals, both of which are detrimental to social welfare. Furthermore, (13) shows that as the magnitude of investment externality $\alpha$ increases, the weight placed on minimizing fundamental uncertainty decreases whereas the weight placed on the additional costs of accounting harmonization increases. Accordingly, higher investment externality requires the optimal accounting standards to be less harmonized.

The following proposition yields additional comparative statics regarding the optimal degree of accounting harmonization $m^{*}$ to generate further implications.

Corollary 2 For any $\alpha \in[0,1)$, the optimal degree of harmonization $m^{*}$ is

1. increasing in the precision of any signal about the common fundamental $\theta$, i.e., $\frac{\partial m^{*}}{\partial h_{\theta}}>0$, $\frac{\partial m^{*}}{\partial h_{\eta}}>0, \frac{\partial m^{*}}{\partial h_{\xi_{1}}}>0$

2. decreasing in the precision of any signal about the idiosyncratic fundamental $\lambda_{i}$, i.e., $\frac{\partial m^{*}}{\partial h_{\lambda}}<0, \frac{\partial m^{*}}{\partial h_{\varepsilon}}<0, \frac{\partial m^{*}}{\partial h_{\xi_{2}}}<0$.

Corollary 2 is intuitive. It states that, when the firms have better information about the common fundamental $\theta$ (e.g., a more precise prior about $\theta$, a more informative private 
signal $s_{i 1}$, or less common reporting noise $\eta$ ), the optimal degree of harmonization $m^{*}$ should be higher. Intuitively, in environments with abundant information about $\theta$, it is more important to reduce the uncertainty about the idiosyncratic fundamental $\lambda_{i}$, corresponding to more harmonized accounting standards. Analogously, when the firms can predict $\lambda_{i}$ more accurately (e.g., a more precise prior about $\lambda_{i}$, a more informative private signal $s_{i 2}$, or less idiosyncratic reporting noise $\left.\varepsilon_{i}\right), m^{*}$ should be set lower as the marginal benefit of further reducing uncertainty about $\lambda_{i}$ diminishes.

\subsection{When mandating harmonized accounting standards is beneficial}

In the previous section, we derive the optimal level of harmonization $m^{*}$ that maximizes social welfare. This solution can be viewed as one made by a benevolent accounting-standard setter, who optimally sets the degree of harmonization $m^{*}$ for every firm or every country. A natural follow-up question is whether each individual firm or country, when given the choice over harmonization, would adopt the socially optimal accounting standards in equilibrium. This question is important as it has implications for whether and when mandating more harmonized accounting standards is beneficial. In other words, had each firm voluntarily adopted the socially optimal accounting standards in equilibrium, there would be no need for mandatory adoption. In this section, we aim to shed some light on this question by solving the firms' private choices of accounting harmonization in our model and comparing the privately optimal choices with the socially optimal choices.

The timeline of this extension is the same as that of the main model except that each firm independently chooses the degree of harmonization in its own accounting standards, denoted by $n_{i} \in[0,1]$, at $t=0$. Each firm $i$ chooses $n_{i}$ to maximize its ex-ante expected firm value $E\left[V_{i}\right]$. In the appendix, we prove that there exists a symmetric equilibrium in which each firm's private choice is denoted by $n^{*}$. Our focus is to examine when $n^{*}$ is different from $m^{*}$, and how the difference depends on the degree of investment externality. These results are summarized in the following proposition.

Proposition 6 The comparison between the firms' private choices of harmonization $n^{*}$ and the socially optimal choice of harmonization $m^{*}$ is as follows: 
1. Absent investment externality $(\alpha=0), m_{0}^{*}<n_{0}^{*}$ if and only if $h_{\eta}\left(h_{\theta}+h_{\xi_{1}}\right)<h_{\varepsilon}\left(h_{\lambda}+h_{\xi_{2}}\right) ;{ }^{10}$

2. When $\alpha>\frac{1}{2}, m^{*}>n^{*}$ always holds.

Proposition 6 indicates that the firm's private choice $n^{*}$ can be higher or lower than the socially optimal $m^{*}$, and interestingly, the difference depends crucially on the degree of investment externality. When the investment externality is absent, the firms may voluntarily choose a higher level of harmonization than the socially optimal level, in which case mandating more harmonized accounting standards is unnecessary. This occurs precisely when firms are relatively better informed about the idiosyncratic fundamental than the common fundamental. This condition seems descriptive of firms' information environment in practice to the extent that firms are typically better informed about firm-specific characteristics relative to industry-level and market-level characteristics (e.g., Piotroski and Roulstone (2004); see also Hutton et al. (2012)). However, when investment externalities are sufficiently high, the firms' private choices always fall short of the level of harmonization that maximizes social welfare, suggesting that mandating more accounting harmonization can be beneficial. In this light, combining Proposition 5 and 6 points to both a cost and a benefit of mandating more harmonized accounting standards in environments with investment externalities. While higher investment externalities call for a lower level of harmonization (Proposition 5), it also justifies the mandatory adoption of (such lower level of) harmonization.

To understand the intuition for Proposition 6, note that there exist two types of externalities in our model. The first type is the information spillovers due to the correlated fundamentals across firms, which is always positive, regardless of the value of $\alpha$. The second one is the investment externality due to firms' investments exhibiting beauty-contest features. The investment externality exists only when $\alpha>0$ and increases in $\alpha$.

Consider first the case that $\alpha=0$ so only the information spillover effect exists. In their private choices of the degree of accounting harmonization, firms face a similar trade-off to that of the standard-setter, in which more harmonized accounting standards improve the amount of information about the idiosyncratic fundamental $\lambda_{i}$ at the expense of reducing

\footnotetext{
${ }^{10}$ Recall that $m_{0}^{*}$ denote the socially optimal level of accounting harmonization in the no-beauty-contest benchmark (given in Proposition 3). Analogously, we denote the privately optimal level of accounting harmonization in the no-beauty-contest benchmark by $n_{0}^{*}$.
} 
the amount of information about the common fundamental $\theta$. Yet, because of the information spillover effect, both the private benefit and cost of accounting harmonization from the firms' perspective are smaller than the social benefit and cost of accounting harmonization. To see this, consider first the private vs. social benefit of accounting harmonization. More harmonized standards not only improve an individual firm's precision in estimating its own idiosyncratic fundamental, but also help all firms to estimate their idiosyncratic fundamentals. However, since an individual firm does not take into account such positive externalities on other firms, it prefers less harmonized accounting standards than the socially optimal level. Next, consider the private vs. social cost of accounting harmonization. Similarly, more harmonized standards reduce the amount of information about common fundamental for all firms; however, an individual firm can only internalize the information loss on its own, thus contemplating a smaller private cost of accounting harmonization than the social cost. This effect alone induces firms to prefer more harmonized accounting standards than the socially optimal level. In total, when the precision of signals regarding the common fundamental is relatively low, it is crucial to generate information about the common fundamental (via adopting less harmonized accounting standards), which makes the cost of accounting harmonization a key consideration for the standard-setter. Accordingly, the standard-setter prefers less harmonized accounting standards than firms. This explains Part 1 of Proposition 6.

Next, we explain how adding investment externalities $(\alpha>0)$ changes the preferences of both the individual firms and the standard-setter for accounting harmonization. Because of the beauty-contest feature, both the individual firms and the standard-setter care about aligning the firms' investments. Furthermore, the standard-setter cares more about such alignment than the firms. This is because an individual firm is only concerned about setting its own investment close to its peers, whereas the standard-setter also cares about aligning the investments of all firms. More harmonized accounting standards help the standard-setter to better align the firms' investments because they make the firms' reports more correlated and thus drive stronger comovements across the firms' investments. As a result, when investment externalities become sufficiently large, the standard-setter would prefer a higher degree of harmonization than what the firms would choose privately, thus making mandating harmonized accounting standards desirable. 


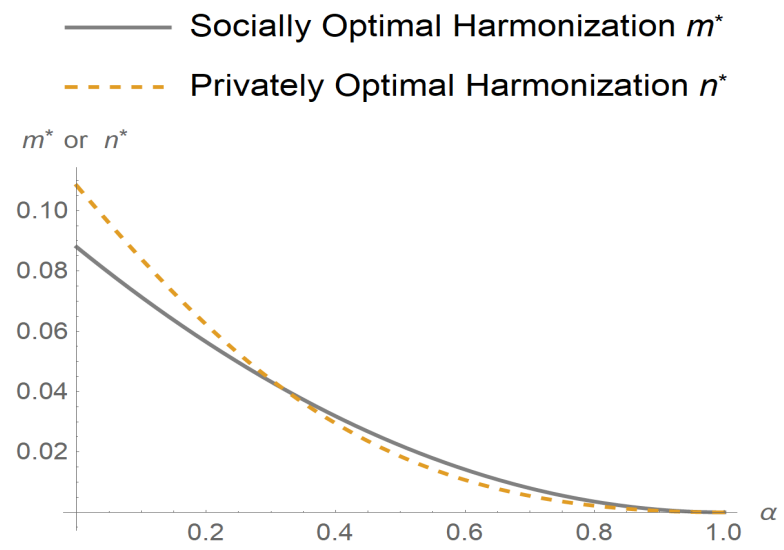

Figure 2: Optimal degree of socially and privately harmonization as a function of investment externality $\alpha$. All other parameters are: $h_{\theta}=0.2, h_{\lambda}=5, h_{\xi_{1}}=0.5, h_{\xi_{2}}=1, h_{\varepsilon}=20, h_{\eta}=3$.

Finally, note that Proposition 6 states that firms may privately choose more harmonized accounting methods than the socially optimal level absent investment externality, and less harmonized methods when the investment externality is sufficiently strong. Therefore, an immediate question is whether there exists some cutoff such that firms privately adopt a lower degree of harmonization if and only if the degree of investment externality is above the cutoff. Although, due to the complexity of our model, we cannot prove this conjecture analytically, numerical analysis suggests that it is indeed true. As shown in Figure 2, the privately optimal harmonization, $n^{*}$, is smaller than the socially optimal harmonization, $m^{*}$, if and only if $\alpha$ is greater than around 0.32 .

\section{Implications}

Our results provide several empirical and regulatory implications. First, Corollary 2 provides empirical implications regarding how investment sensitivity to aggregate earnings varies with the degree of harmonization of accounting standards. Our results predict that when accounting standards become more harmonized (e.g., due to IFRS adoption), a firm's investment will be less sensitive to aggregate earnings reports (equivalent to the average report in our model) and more sensitive to the idiosyncratic portion of the firm's own earnings reports (equivalent to the demeaned report in our model), regardless of the effects of harmonized accounting standards on the precision of earnings. This prediction, if confirmed, will be another example 
of the different associations between earnings and other variables (e.g. stock returns) at the individual firm and the aggregate levels ${ }^{11}$, to the extent that, at the individual firm level, it is often implicitly assumed that firm investment becomes more sensitive to earnings when earnings quality is higher (e.g., Li (2011)), whereas our model predicts that, at the aggregate level, the relation between firm investment and aggregate earnings may not necessarily depend on earnings precision, but rather are driven by accounting harmonization. Yet, to the best of our knowledge, this prediction has not been tested.

Second, Corollary 2 provides empirical predictions regarding how the optimal degree of harmonization varies with respect to the precision of signals about common fundamentals versus that of idiosyncratic fundamentals. Industries/countries exhibiting more correlated fundamentals (i.e., the variance of $\theta$ is much higher than that of $\lambda_{i}$ ) should adopt less harmonized accounting standards. ${ }^{12}$ Similarly, countries in which the association between aggregate earnings and GDP growth is stronger relative to the association between firm-level earnings and firm value should adopt more harmonized accounting standards. ${ }^{13}$ This may provide an alternative explanation of why certain industries/countries are less willing to adopt IFRS.

Third, our results suggest that the optimal degree of harmonization of accounting standards depends on the degree of the beauty-contest motive. A higher beauty-contest motive demands less harmonized accounting standards. This suggests that a one-size-fits-all harmonization of accounting standards is not desirable, to the extent that different countries or industries exhibit different degrees of beauty-contest motive. Our results suggest that industries or countries that are prone to such beauty-contest motive (e.g., financial industries or countries where financial industries are very important) should adopt less harmonized accounting standards, and perhaps maintain their own local accounting standards. Accordingly, our results predict that when an entire country or region adopts common accounting standards (e.g., the European Union's adoption of IFRS), industries in the adopting country or countries in the adopting region that exhibit higher degrees of beauty-contest motive would

\footnotetext{
${ }^{11}$ See Ball and Sadka (2015) for an excellent review of the literature on aggregate earnings.

${ }^{12}$ Fang et al. (2019) have a similar prediction and find empirical evidence supporting the prediction.

${ }^{13}$ To see this more precisely, note that from Proposition 4, the association between the aggregate investment $K$ and the aggregate earnings $\bar{r}$ is strictly increasing in the precision of the common noise $\eta$, i.e., $h_{\eta}$, whereas the association between the individual firm's investment $k_{i}$ and the firm-level earning $v_{i}$ is strictly increasing in the precision of the idiosyncratic noise $\varepsilon_{i}$, i.e., $h_{\varepsilon}$. By Corollary 2 , when $h_{\eta}$ is relatively larger than $h_{\varepsilon}$, the optimal degree of accounting harmonization $m^{*}$ should be higher.
} 
be less likely to obtain incremental benefits from such adoption than the ones that exhibit lower degrees of beauty-contest motive.

Finally, our results also provide a justification for the recent mandatory adoption of more harmonized accounting standards such as IFRS adoption, as firms, when given the choice over harmonization, may choose less harmonized accounting standards than the socially optimal choice. This could happen especially when the beauty-contest motive is sufficiently strong. For firms and industries that exhibit weak beauty-contest motives, however, mandating more harmonized accounting standards is unnecessary as firms voluntarily would choose to adopt even more harmonized accounting standards. One implication of our results is that early voluntary adopters of common accounting standards will be more likely from those industries that exhibit lower degrees of beauty-contest motive.

\section{Conclusion}

We analytically study the optimal degree of harmonization of accounting standards in a setting that exhibits beauty-contest features. We find that the optimal degree of harmonization depends on the strength of such beauty-contest feature. Specifically, when the beauty-contest feature is strong, forecasting others' behavior (i.e., strategic uncertainty) becomes crucial, and therefore calls for a lower degree of harmonization to reduce strategic uncertainty. We also find that when beauty-contest feature is very important, mandatory adoption of harmonized accounting standards becomes desirable as firms voluntarily choose an even lower degree of harmonization. Our results provide both empirical and regulatory implications and suggest that the strength of beauty-contest motives is an important consideration in determining the degree of accounting standards harmonization.

Our work can be extended in a couple of dimensions. First, our study focuses on investment efficiency and does not explicitly model capital markets and investors' trading decisions. Future work can incorporate capital markets and study how more harmonized accounting standards affect both the firms' investment decisions and the investors' trading decisions when investments exhibit beauty-contest features. Second, while our investment beauty-contest model captures strategic complementarity that is relevant to financial institu- 
tions, it does not directly model the salient institutional features of banks, e.g., the mismatch between assets and liabilities and the liquidity needs of depositors. Future work can explicitly model those features and shed light on how harmonized accounting standards affect the banking sector, and in particular, systemic bank runs. 


\section{Appendix I: Proofs}

Proof. of Lemma 1: Given $\bar{r}=\theta+m \eta$, we can express firm $i$ 's accounting report $r_{i}$ as $r_{i}=\bar{r}+v_{i}$, where $v_{i}=\lambda_{i}+(1-m) \varepsilon_{i}$. It is easy to see that $v_{i}$ is independent and identically distributed over the population $i \in[0,1]$, and $v_{i} \sim N\left(0, \frac{1}{h_{\lambda}}+\frac{(1-m)^{2}}{h_{\varepsilon}}\right)$. Furthermore, because $v_{i}$ is independent of $\theta, \theta \mid \bar{r}, v_{i}$ is equivalent to $\theta \mid \bar{r}$, i.e., $\bar{r}$ is a sufficient statistic for $\theta$.

Similarly, given $v_{i}=\lambda_{i}+(1-m) \varepsilon_{i}$, we can express firm $i$ 's accounting report $r_{i}$ as $r_{i}=v_{i}+\bar{r}$, where $\bar{r}=\theta+m \eta$ is independent of $\lambda_{i}$. That is, $r_{i}$ does not provide additional information to estimate $\lambda_{i}$ conditional on $v_{i}$. Meanwhile, any other firm's report $r_{j}$ is always independent of $\lambda_{i}$ and thus is never useful in estimating $\lambda_{i}$. Therefore, $v_{i}$ is a sufficient statistic for $\lambda_{i}$.

Proof. of Proposition 1: Given Lemma 1, the conditional distribution of $\lambda_{i} \mid r_{i}, r_{-i}, s_{i 1}, s_{i 2}$ is equivalent to that of $\lambda_{i} \mid v_{i}, s_{i 2}$. As $v_{i}=\lambda_{i}+(1-m) \varepsilon_{i}$, and $s_{i 2}=\theta+\xi_{2}$,

$$
\lambda_{i} \mid v_{i}, s_{i 2} \sim N\left(\frac{\frac{h_{\varepsilon}}{(1-m)^{2}} v_{i}+h_{\xi_{2}} s_{i 2}}{h_{\lambda}+\frac{h_{\varepsilon}}{(1-m)^{2}}+h_{\xi_{2}}}, \frac{1}{h_{\lambda}+\frac{h_{\varepsilon}}{(1-m)^{2}}+h_{\xi_{2}}}\right) .
$$

It is easy to see that $\operatorname{Var}_{i}\left(\lambda_{i}\right)=\frac{1}{h_{\lambda}+\frac{h_{\varepsilon}}{(1-m)^{2}}+h_{\xi_{2}}}$ is strictly decreasing in $m$.

Similarly, the conditional distribution of $\theta \mid r_{i}, r_{-i}, s_{i 1}, s_{i 2}$ is equivalent to that of $\theta \mid \bar{r}, s_{i 1}$. As $\bar{r}=\theta+m \eta$ and $s_{i 1}=\theta+\xi_{1}$,

$$
\theta \mid \bar{r}, s_{i 1} \sim N\left(\frac{h_{\theta} \mu_{\theta}+\frac{h_{\eta}}{m^{2}} \bar{r}+h_{\xi_{1}} s_{i 1}}{h_{\theta}+\frac{h_{\eta}}{m^{2}}+h_{\xi_{1}}}, \frac{1}{h_{\theta}+\frac{h_{\eta}}{m^{2}}+h_{\xi_{1}}}\right) .
$$

The conditional variance $\operatorname{Var}_{i}(\theta)=\frac{1}{h_{\theta}+\frac{h_{\eta}}{m^{2}}+h_{\xi_{1}}}$ is strictly increasing in $m$.

Proof. of Proposition 2: As shown in the proof of Proposition 1, firm i's forecast on its fundamental, $\theta_{i}$, satisfies

$$
\begin{aligned}
E_{i}\left[\theta_{i}\right] & =\frac{h_{\theta} \mu_{\theta}+\frac{h_{\eta}}{m^{2}} \bar{r}+h_{\xi_{1}} s_{i 1}}{h_{\theta}+\frac{h_{\eta}}{m^{2}}+h_{\xi_{1}}}+\frac{\frac{h_{\varepsilon}}{(1-m)^{2}} v_{i}+h_{\xi_{2}} s_{i 2}}{h_{\lambda}+\frac{h_{\varepsilon}}{(1-m)^{2}}+h_{\xi_{2}}}, \\
\operatorname{Var}_{i}\left(\theta_{i}\right) & =\frac{1}{h_{\theta}+\frac{h_{\eta}}{m^{2}}+h_{\xi_{1}}}+\frac{1}{h_{\lambda}+\frac{h_{\varepsilon}}{(1-m)^{2}}+h_{\xi_{2}}} .
\end{aligned}
$$


The average forecast on firms' own fundamental is

$$
\bar{E}\left[\theta_{j}\right]=\int_{0}^{1} E_{j}\left[\theta_{j}\right] d j=\frac{h_{\theta} \mu_{\theta}+\frac{h_{\eta}}{m^{2}} \bar{r}+h_{\xi_{1}} \theta}{h_{\theta}+\frac{h_{\eta}}{m^{2}}+h_{\xi_{1}}} .
$$

Therefore, firm $i$ 's forecast on $\bar{E}\left[\theta_{j}\right]$ is equivalent to

$$
\begin{aligned}
E_{i}\left[\bar{E}\left[\theta_{j}\right]\right] & =\frac{h_{\theta} \mu_{\theta}+\frac{h_{\eta}}{m^{2}} \bar{r}}{h_{\theta}+\frac{h_{\eta}}{m^{2}}+h_{\xi_{1}}}+\rho E_{i}[\theta], \\
\operatorname{Var}_{i}\left(\bar{E}\left[\theta_{j}\right]\right) & =\rho^{2} \operatorname{Var}_{i}(\theta)=\rho^{2} \frac{1}{h_{\theta}+\frac{h_{\eta}}{m^{2}}+h_{\xi_{1}}},
\end{aligned}
$$

where $\rho=\frac{h_{\xi_{1}}}{h_{\theta}+\frac{h_{\eta}}{m^{2}}+h_{\xi_{1}}}$. Obviously, $\operatorname{Var}_{i}\left(\bar{E}\left[\theta_{j}\right]\right)$ is strictly increasing in $m$.

Proof. of Proposition 3: By equation (8), $m$ affects $W$ only through the effect of $\operatorname{Var}_{i}\left(\theta_{i}\right)$. Furthermore, Proposition 1 suggests that

$$
\operatorname{Var}_{i}\left(\theta_{i}\right)=\frac{1}{h_{\theta}+\frac{h_{\eta}}{m^{2}}+h_{\xi_{1}}}+\frac{1}{h_{\lambda}+\frac{h_{\varepsilon}}{(1-m)^{2}}+h_{\xi_{2}}}
$$

Take the first-order condition with respect to $m$, and it yields

$$
\frac{\partial \operatorname{Var}_{i}\left(\theta_{i}\right)}{\partial m}=\frac{2 m h_{\eta}}{\left[m^{2}\left(h_{\theta}+h_{\xi_{1}}\right)+h_{\eta}\right]^{2}}+\frac{2(m-1) h_{\varepsilon}}{\left[(1-m)^{2}\left(h_{\lambda}+h_{\xi_{2}}\right)+h_{\varepsilon}\right]^{2}}
$$

It is easy to see that at the two extreme values of $m$ :

$$
\begin{aligned}
\left.\frac{\partial \operatorname{Var}_{i}\left(\theta_{i}\right)}{\partial m}\right|_{m=1} & =\frac{2 h_{\eta}}{\left[\left(h_{\theta}+h_{\xi_{1}}\right)+h_{\eta}\right]^{2}}>0 ; \\
\left.\frac{\partial \operatorname{Var}_{i}\left(\theta_{i}\right)}{\partial m}\right|_{m=0} & =\frac{-2 h_{\varepsilon}}{\left[\left(h_{\lambda}+h_{\xi_{2}}\right)+h_{\varepsilon}\right]}<0 .
\end{aligned}
$$

That is, at $m=1, \operatorname{Var}_{i}\left(\theta_{i}\right)$ is strictly increasing in $m$, while at $m=0, \operatorname{Var}_{i}\left(\theta_{i}\right)$ is strictly decreasing in $m$. Therefore, the optimal $m_{0}^{*}$ is always interior.

Proof. of Proposition 4: The proof proceeds in two steps. We first examine the firm's investment strategy using the guess-and-verify approach, and then compare the coefficient with the benchmark $(\alpha=0)$. 
Step 1) We conjecture that each firm's investment is

$$
k_{i}=\psi_{0}+\psi_{\bar{r}} \bar{r}+\psi_{v} v_{i}+\psi_{s_{1}} s_{i 1}+\psi_{s_{2}} s_{i 2}
$$

and thus aggregate investment is

$$
K=\int_{0}^{1} k_{i} d i=\psi_{0}+\psi_{\bar{r}} \bar{r}+\psi_{s_{1}} \theta
$$

Therefore, firm $i$ 's forecast of $K$ is $E_{i}[K]=\psi_{0}+\psi_{\bar{r}} \bar{r}+\psi_{s_{1}} E_{i}[\theta]$. Plugging $E_{i}[K]$ in equation (9) results in

$$
\begin{aligned}
k_{i} & =(1-\alpha) E_{i}\left[\theta_{i}\right]+\alpha E_{i}[K] \\
& =\psi_{0}+\psi_{\bar{r}} \bar{r}+\left[(1-\alpha)+\alpha \psi_{s_{1}}\right] E_{i}[\theta]+(1-\alpha) E_{i}\left[\lambda_{i}\right] \\
& =\psi_{0}+\psi_{\bar{r}} \bar{r}+\left[(1-\alpha)+\alpha \psi_{s_{1}}\right] \frac{h_{\theta} \mu_{\theta}+\frac{h_{\eta}}{m^{2}} \bar{r}+h_{\xi_{1}} s_{i 1}}{h_{\theta}+\frac{h_{\eta}}{m^{2}}+h_{\xi_{1}}}+(1-\alpha) \frac{\frac{h_{\varepsilon}}{(1-m)^{2}} v_{i}+h_{\xi_{2}} s_{i 2}}{h_{\lambda}+\frac{h_{\varepsilon}}{(1-m)^{2}}+h_{\xi_{2}}} .
\end{aligned}
$$

Match coefficient with the conjectured investment:

$$
\begin{aligned}
\psi_{0} & =\psi_{0}+\left[(1-\alpha)+\alpha \psi_{s_{1}}\right] \frac{h_{\theta} \mu_{\theta}}{h_{\theta}+\frac{h_{\eta}}{m^{2}}+h_{\xi_{1}}} ; \\
\psi_{\bar{r}} & =\psi_{\bar{r}}+\left[(1-\alpha)+\alpha \psi_{s_{1}}\right] \frac{\frac{h_{\eta}}{m^{2}}}{h_{\theta}+\frac{h_{\eta}}{m^{2}}+h_{\xi_{1}}} ; \\
\psi_{s_{1}} & =\left[(1-\alpha)+\alpha \psi_{s_{1}}\right] \frac{h_{\xi_{1}}}{h_{\theta}+\frac{h_{\eta}}{m^{2}}+h_{\xi_{1}}} ; \\
\psi_{v} & =(1-\alpha) \frac{\frac{h_{\varepsilon}}{(1-m)^{2}}}{h_{\lambda}+\frac{h_{\varepsilon}}{(1-m)^{2}}+h_{\xi_{2}}} ; \\
\psi_{s_{2}} & =(1-\alpha) \frac{h_{\xi_{2}}}{h_{\lambda}+\frac{h_{\varepsilon}}{(1-m)^{2}}+h_{\xi_{2}}}
\end{aligned}
$$

Solve the system of equations and it yields $k_{i}=\frac{h_{\theta} \mu_{\theta}+\frac{h_{\eta}}{m^{2}} \bar{r}+(1-\alpha) h_{\xi_{1}} s_{i 1}}{h_{\theta}+\frac{h_{\eta}}{m^{2}}+(1-\alpha) h_{\xi_{1}}}+(1-\alpha) \frac{\frac{h_{\varepsilon}}{(1-m)^{2}} v_{i}+h_{\xi_{2}} s_{i 2}}{h_{\lambda}+\frac{h_{\varepsilon}}{(1-m)^{2}}+h_{\xi_{2}}}$.

Step 2) recall that by equation (7), firm $i$ 's investment in the case of $\alpha=0$ is

$$
k_{i}=E_{i}\left[\theta_{i}\right]=\frac{h_{\theta} \mu_{\theta}+\frac{h_{\eta}}{m^{2}} \bar{r}+h_{\xi_{1}} s_{i 1}}{h_{\theta}+\frac{h_{\eta}}{m^{2}}+h_{\xi_{1}}}+\frac{\frac{h_{\varepsilon}}{(1-m)^{2}} v_{i}+h_{\xi_{2}} s_{i 2}}{h_{\lambda}+\frac{h_{\varepsilon}}{(1-m)^{2}}+h_{\xi_{2}}} .
$$


When $\alpha>0$, the investment follows equation (9) shows. Compare the weight on $\bar{r}$ versus that on $s_{i 1}$, it is obvious that each firm always over-weights $\bar{r}$ and under-weights $s_{i 1}$ relative to the benchmark of $\alpha=0$, and the over-weight is more severe when $\alpha$ is larger. On the other hand, the weight on $v_{i}$ versus that on $s_{i 2}$ is independent of $\alpha$. That is, the firm does not over-weights or under-weight the two signals.

Proof. of Corollary 1: Obviously, $\psi_{\bar{r}}=\frac{\frac{h_{\eta}}{m^{2}}}{h_{\theta}+\frac{h_{\eta}}{m^{2}}+h_{\xi_{1}}}$ decreases in $m$ and $\psi_{s_{1}}=\frac{h_{\xi_{1}}}{h_{\theta}+\frac{h_{\eta}}{m^{2}}+h_{\xi_{1}}}$ increases in $m$. Furthermore, $\psi_{\bar{r}}+\psi_{s_{1}}=1-\frac{h_{\theta}}{h_{\theta}+\frac{h_{\eta}}{m^{2}}+h_{\xi_{1}}}$ decreases in $m$. By contrast, $\psi_{v}=\frac{\frac{h_{\varepsilon}}{(1-m)^{2}}}{h_{\lambda}+\frac{h_{\varepsilon}}{(1-m)^{2}}+h_{\xi_{2}}}$ increases in $m$ and $\psi_{s_{2}}=\frac{h_{\xi_{2}}}{h_{\lambda}+\frac{h_{\varepsilon}}{(1-m)^{2}}+h_{\xi_{2}}}$ decreases in $m$. Meanwhile, $\psi_{v}+\psi_{s_{2}}=1-\frac{h_{\lambda}}{h_{\lambda}+\frac{h_{\varepsilon}}{(1-m)^{2}}+h_{\xi_{2}}}$ increases in $m$.

Proof. of Proposition 5: The proof proceeds in the following steps. In step 1, we will decompose social welfare as in equation (13), and examine the effect of $m$ on each term separately. In step 2, we will show that Assumption 1 is sufficient to guarantee the optimal $m^{*}$ is unique for any $\alpha \in[0,1)$. In step 3 , we will compare the optimal $m^{*}$ (when $\alpha>0$ ) versus $m_{0}^{*}$ (when $\alpha=0$ ). In step 4 , we will prove a general result that $\frac{\partial m^{*}}{\partial \alpha}<0$.

Step 1) Given each firm's investment in equation (9), the expected payoff for firm $i$ is

$$
E_{i}\left[R_{i} k_{i}-\frac{k_{i}^{2}}{2}\right]=\frac{\left(E_{i}\left[R_{i}\right]\right)^{2}}{2}=\frac{1}{2}\left\{(1-\alpha) E_{i}\left[\theta_{i}\right]+\alpha E_{i}[K]\right\}^{2} .
$$

Therefore, the ex-ante social welfare can be expressed as

$$
W=(1-\alpha)^{2} \frac{E\left[\left(E_{i}\left[\theta_{i}\right]\right)^{2}\right]}{2}+\frac{\alpha^{2}}{2} E\left[\left(E_{i}[K]\right)^{2}\right]+\alpha(1-\alpha) E\left[E_{i}\left[\theta_{i}\right] E_{i}[K]\right]
$$

As shown in the benchmark $(\alpha=0)$, the first term $\frac{E\left[\left(E_{i}\left[\theta_{i}\right]\right)^{2}\right]}{2}=\frac{\mu_{\theta}^{2}+\operatorname{Var}\left(\theta_{i}\right)-\operatorname{Var}_{i}\left(\theta_{i}\right)}{2}$, and $m$ leads to a trade-off of balancing $\operatorname{Var}_{i}(\theta)$ versus $\operatorname{Var}_{i}\left(\lambda_{i}\right)$.

To see the second term, notice that each firm anticipates that the equilibrium $K$ follows equation (12). Therefore,

$$
E\left[\left(E_{i}[K]\right)^{2}\right]=E\left[E_{i}\left[K^{2}\right]-\operatorname{Var}_{i}(K)\right]=[E[K]]^{2}+\operatorname{Var}(K)-\operatorname{Var}_{i}(K)
$$


where the second equation uses two facts that 1) the law of iterated expectation implies $E\left[E_{i}\left[K^{2}\right]\right]=E\left[K^{2}\right]=[E[K]]^{2}+\operatorname{Var}(K)$ and 2) $\operatorname{Var}_{i}(K)$ is the same for each firm, i.e., $E\left[\operatorname{Var}_{i}(K)\right]=\operatorname{Var}_{i}(K)$. By equation (12),

$$
\operatorname{Var}_{i}(K)=\psi_{s_{1}} \operatorname{Var}_{i}(\theta)=\left[\frac{(1-\alpha) h_{\xi_{1}}}{h_{\theta}+\frac{h_{\eta}}{m^{2}}+(1-\alpha) h_{\xi_{1}}}\right]^{2} \frac{1}{h_{\theta}+\frac{h_{\eta}}{m^{2}}+h_{\xi_{1}}}
$$

which increases in $m$. Meanwhile, to assess the ex-ante mean and variance of $K$, we rewrite

$$
K=\psi_{0}+\psi_{\bar{r}} \bar{r}+\psi_{s_{1}} \theta=\psi_{0}+\left(\psi_{\bar{r}}+\psi_{s_{1}}\right) \theta+\psi_{\bar{r}} \cdot m \eta
$$

Obviously, $E[K]=\mu_{\theta}$ is a constant. For the ex-ante variance,

$$
\begin{aligned}
\operatorname{Var}(K) & =\left(\psi_{\bar{r}}+\psi_{s_{1}}\right)^{2} \operatorname{Var}(\theta)+\left(\psi_{\bar{r}}\right)^{2} \operatorname{Var}(m \eta) \\
& =\frac{\left[\frac{h_{\eta}}{m^{2}}+(1-\alpha) h_{\xi_{1}}\right]^{2} \frac{1}{h_{\theta}}+\frac{h_{\eta}}{m^{2}}}{\left[h_{\theta}+\frac{h_{\eta}}{m^{2}}+(1-\alpha) h_{\xi_{1}}\right]^{2}}
\end{aligned}
$$

It is easy to see that

$$
\frac{\partial \operatorname{Var}(K)}{\partial m}=-\frac{2 m h_{\eta}\left[h_{\eta}+\left(h_{\theta}+3(1-\alpha) h_{\xi_{1}}\right) m^{2}\right]}{\left[h_{\eta}+m^{2}\left(h_{\theta}+(1-\alpha) h_{\xi_{1}}\right)\right]^{3}}<0
$$

Taken together, the second term strictly decreases in $m$ as the following equation shows:

$$
E\left[\left(E_{i}[K]\right)^{2}\right]=\underbrace{[E[K]]^{2}}_{\text {constant }}+\underbrace{\operatorname{Var}(K)}_{\text {decreases in } m}-\underbrace{\operatorname{Var}_{i}(K)}_{\text {increases in } m} .
$$

For the third term, notice that because $E_{i}\left[\lambda_{i}\right]$ and $E_{i}[K]$ consist of orthogonal signals, we can further simplify

$$
E\left[E_{i}\left[\theta_{i}\right] E_{i}[K]\right]=E\left[E_{i}[\theta] E_{i}[K]+E_{i}\left[\lambda_{i}\right] E_{i}[K]\right]=E\left[E_{i}[\theta] E_{i}[K]\right]
$$

Since $E\left[E_{i}[\theta]\right]=E\left[E_{i}[K]\right]=\mu_{\theta}$,

$$
E\left[E_{i}[\theta] E_{i}[K]\right]=\mu_{\theta}^{2}+\operatorname{Cov}\left(E_{i}[\theta], E_{i}[K]\right) .
$$


By the law of total covariance,

$$
\operatorname{Cov}\left(E_{i}[\theta], E_{i}[K]\right)=\operatorname{Cov}(\theta, K)-E\left[\operatorname{Cov}_{i}[\theta, K]\right]=\operatorname{Cov}(\theta, K)-\operatorname{Cov}_{i}(\theta, K),
$$

where the second equation uses the fact that $\operatorname{Cov}_{i}(\theta, K)$ is the same for any signal realizations, i.e., $E\left[\operatorname{Cov}_{i}(\theta, K)\right]=\operatorname{Cov}_{i}(\theta, K)$. Now, we can analyze the effect of $m$ on $\operatorname{Cov}(\theta, K)$ and $\operatorname{Cov}_{i}(\theta, K)$ respectively. Using equation (16),

$$
\operatorname{Cov}(\theta, K)=\left(\psi_{\bar{r}}+\psi_{s_{1}}\right) \operatorname{Var}(\theta)
$$

which strictly decreases in $m$ by Corollary 1 . On the other hand,

$$
\operatorname{Cov}_{i}(\theta, K)=\operatorname{Cov}_{i}\left(\theta, \psi_{0}+\psi_{\bar{r}} \bar{r}+\psi_{s_{1}} \theta\right)=\psi_{s_{1}} \operatorname{Var}_{i}(\theta)
$$

which strictly increases in $m$ because both $\psi_{s_{1}}$ and $\operatorname{Var}_{i}(\theta)$ are increasing in $m$. Taken together, the last term strictly decreases in $m$ as the following equation shows:

$$
E\left[E_{i}\left[\theta_{i}\right] E_{i}[K]\right]=\underbrace{\mu_{\theta}^{2}}_{\text {constant }}+\underbrace{\operatorname{Cov}(\theta, K)}_{\text {decreases in } m}-\underbrace{\operatorname{Cov}_{i}(\theta, K)}_{\text {increases in } m}
$$

Step 2) When $\alpha=0$, it is easy to verify that

$$
\frac{\partial^{2} \operatorname{Var}_{i}\left(\theta_{i}\right)}{\partial m^{2}}=\frac{2 h_{\eta}\left[h_{\eta}-3\left(h_{\theta}+h_{\xi_{1}}\right) m^{2}\right]}{\left[m^{2}\left(h_{\theta}+h_{\xi_{1}}\right)+h_{\eta}\right]^{3}}+\frac{2 h_{\varepsilon}\left[h_{\varepsilon}-3\left(h_{\theta}+h_{\xi_{1}}\right)(1-m)^{2}\right]}{\left[(1-m)^{2}\left(h_{\lambda}+h_{\xi_{2}}\right)+h_{\varepsilon}\right]^{3}} .
$$

Given assumption 1 , it is easy to see that $\frac{\partial^{2} \operatorname{Var}_{i}\left(\theta_{i}\right)}{\partial m^{2}}>0$ is always satisfied for any $m \in[0,1]$, suggesting $\operatorname{Var}_{i}\left(\theta_{i}\right)$ is strictly convex. Therefore, the first-order condition in equation (14) gives rise to the unique optimal $m_{0}^{*}$ that minimizes $\operatorname{Var}_{i}\left(\theta_{i}\right)$.

In a similar way, when $\alpha>0$, we examine the second-order condition $\frac{\partial^{2} W}{\partial m^{2}}$. As shown in 
step 1,

$$
\begin{aligned}
W= & \operatorname{const}+\frac{(1-\alpha)^{2}}{2}\left[\operatorname{Var}\left(\lambda_{i}\right)-\operatorname{Var}_{i}\left(\lambda_{i}\right)\right]+\frac{(1-\alpha)^{2}}{2}\left[\operatorname{Var}(\theta)-\operatorname{Var}_{i}(\theta)\right] \\
& +\frac{\alpha^{2}}{2}\left[\operatorname{Var}(K)-\operatorname{Var}_{i}(K)\right]+\alpha(1-\alpha)\left[\operatorname{Cov}(\theta, K)-\operatorname{Cov}_{i}(\theta, K)\right]
\end{aligned}
$$

For ease of exposition, we denote $B=\frac{(1-\alpha)^{2}}{2}\left[\operatorname{Var}\left(\lambda_{i}\right)-\operatorname{Var}_{i}\left(\lambda_{i}\right)\right]$, where $B$ stands for "benefit"; and $C=W-$ const $-B$, where $C$ stands for "cost". It is easy to verify that

$$
\frac{\partial^{2} B}{\partial m^{2}} \propto-\frac{(1-\alpha)^{2}}{2} 2 h_{\varepsilon}\left[h_{\varepsilon}-3\left(h_{\lambda}+h_{\xi_{2}}\right)(1-m)^{2}\right]
$$

which is negative given $h_{\varepsilon}>3\left(h_{\lambda}+h_{\xi_{2}}\right)$. In addition,

$\frac{\partial^{2} C}{\partial m^{2}} \propto\left[3\left(h_{\theta}+(1-\alpha) h_{\xi_{1}}\right) m^{2}-h_{\eta}\right]\left[\left(h_{\theta}+\left(1+\alpha-2 \alpha^{2}\right) h_{\xi_{1}}\right) m^{2}+h_{\eta}\right]-4 h_{\eta} h_{\xi_{1}} \alpha(1-\alpha) m^{2}$.

If $h_{\eta}>3\left(h_{\theta}+h_{\xi_{1}}\right), 3\left(h_{\theta}+(1-\alpha) h_{\xi_{1}}\right) m^{2}-h_{\eta}<0$ and thus $\frac{\partial^{2} C}{\partial m^{2}}<0$. Taken together, assumption 1 guarantees $\frac{\partial^{2} W}{\partial m^{2}}<0$, and therefore the unique solution to the first-order condition maximizes social welfare.

Step 3) When $\alpha>1$, as shown in step 1,

$$
\begin{aligned}
\frac{\partial W}{\partial m}= & \frac{(1-\alpha)^{2}}{2} \underbrace{\frac{\partial\left[\operatorname{Var}\left(\lambda_{i}\right)-\operatorname{Var}_{i}\left(\lambda_{i}\right)\right]}{\partial m}}_{>0}+\frac{(1-\alpha)^{2}}{2} \underbrace{\frac{\partial\left[\operatorname{Var}(\theta)-\operatorname{Var}_{i}(\theta)\right]}{\partial m}}_{<0} \\
& +\frac{\alpha^{2}}{2} \underbrace{\frac{\partial\left[\operatorname{Var}(K)-\operatorname{Var}_{i}(K)\right]}{\partial m}}_{<0}+\alpha(1-\alpha) \underbrace{\frac{\partial \operatorname{Cov}\left(E_{i}[\theta], E_{i}[K]\right)}{\partial m}}_{<0} .
\end{aligned}
$$

In step 2, we already show $\frac{\partial^{2} W}{\partial m^{2}}<0$, and therefore the solution to $\frac{\partial W}{\partial m}=0$ is the unique optimal, denoted as $m^{*}$. Since $\frac{\partial^{2} W}{\partial m^{2}}<0$, for any $m_{1} \in[0,1]$, the following two conditions are equivalent (1) $m_{1}>m^{*}$ and $\left.(2) \frac{\partial W}{\partial m}\right|_{m=m_{1}}<0$. On the other hand, recall that $m_{0}^{*}$ is the unique solution to equation (14), i.e.,

$$
\left.\frac{\partial\left[\operatorname{Var}\left(\lambda_{i}\right)-\operatorname{Var}_{i}\left(\lambda_{i}\right)\right]}{\partial m}\right|_{m=m_{0}^{*}}+\left.\frac{\partial\left[\operatorname{Var}(\theta)-\operatorname{Var}_{i}(\theta)\right]}{\partial m}\right|_{m=m_{0}^{*}}=0
$$

Plugging $m_{0}^{*}$ in equation (17) and apparently $\left.\frac{\partial W}{\partial m}\right|_{m=m_{0}^{*}}<0$, which suggests $m_{0}^{*}>m^{*}$. 
Step 4) Recall that

$$
B=\frac{(1-\alpha)^{2}}{2}\left[\operatorname{Var}\left(\lambda_{i}\right)-\operatorname{Var}_{i}\left(\lambda_{i}\right)\right]=\frac{(1-\alpha)^{2}}{2}\left[\frac{1}{h_{\lambda}}-\frac{1}{h_{\lambda}+\frac{h_{\varepsilon}}{(1-m)^{2}}+h_{\xi_{2}}}\right] \text {, }
$$

that is, $\alpha$ affects $B$ only to the extent of the term $\frac{(1-\alpha)^{2}}{2}$. Therefore, it is easy to see that $\frac{\partial^{2} B}{\partial m \partial \alpha} \propto-\frac{\partial B}{\partial m}<0$. On the other hand, after some algebra, we can show that

$$
\frac{\partial^{2} C}{\partial m \partial \alpha} \propto-4 h_{\xi_{1}} h_{\eta} m^{3}(1-\alpha)\left(2 h_{\theta} m^{2}+2 h_{\eta}+h_{\xi_{1}}(2+\alpha) m^{2}\right)<0 .
$$

Taken together, $\frac{\partial^{2} W}{\partial m \partial \alpha}=\frac{\partial^{2}(B+C)}{\partial m \partial \alpha}<0$. By the implicit function theorem,

$$
\frac{\partial m^{*}}{\partial \alpha}=-\frac{\frac{\partial^{2} W}{\partial m \partial \alpha}}{\frac{\partial^{2} W}{\partial m^{2}}}<0
$$

Proof. of Corollary 2: Recall that $m^{*}$ is the unique solution of $\frac{\partial W}{\partial m}=0$. By the implicit function theorem, for any variable $x$,

$$
\frac{\partial m^{*}}{\partial x}=-\frac{\frac{\partial^{2} W}{\partial m \partial x}}{\frac{\partial^{2} W}{\partial m^{2}}} \propto \frac{\partial^{2} W}{\partial m \partial x}
$$

which is because $\frac{\partial^{2} W}{\partial m^{2}}<0$. As shown in the proof of Proposition 5, we decompose social welfare into two components, $B$ and $C$. Obviously, $h_{\lambda}, h_{\varepsilon}$ and $h_{\xi_{2}}$ affects $W$ only through the effect of $B$, while $h_{\theta}, h_{\eta}$ and $h_{\xi_{1}}$ affects $W$ only through the effect of $C$. Therefore, it is easy to verify that

$$
\frac{\partial^{2} W}{\partial m \partial h_{\lambda}}=\frac{\partial^{2} B}{\partial m \partial h_{\lambda}}=\frac{(1-\alpha)^{2}}{2} \frac{-4 h_{\varepsilon}}{\left(h_{\lambda}+\frac{h_{\varepsilon}}{(1-m)^{2}}+h_{\xi_{2}}\right)^{3}(1-m)^{3}}<0,
$$


Additionally, because $h_{\varepsilon}>3\left(h_{\lambda}+h_{\xi_{2}}\right)$,

$$
\begin{aligned}
\frac{\partial^{2} W}{\partial m \partial h_{\varepsilon}} & =\frac{\partial^{2} B}{\partial m \partial h_{\varepsilon}}=\frac{(1-\alpha)^{2}}{2} \frac{2(1-m)\left[\left(h_{\lambda}+h_{\xi_{2}}\right)(1-m)^{2}-h_{\varepsilon}\right]}{\left[\left(h_{\lambda}+h_{\xi_{2}}\right)(1-m)^{2}+h_{\varepsilon}\right]^{3}}<0 \\
\frac{\partial^{2} W}{\partial m h_{\xi_{2}}} & =\frac{\partial^{2} B}{\partial m \partial h_{\xi_{2}}}=\frac{(1-\alpha)^{2}}{2} \frac{-4 h_{\varepsilon}}{\left(h_{\lambda}+\frac{h_{\varepsilon}}{(1-m)^{2}}+h_{\xi_{2}}\right)^{3}(1-m)^{3}}<0
\end{aligned}
$$

Taken together, we have $\frac{\partial m^{*}}{\partial h_{\lambda}}<0, \frac{\partial m^{*}}{\partial h_{\varepsilon}}<0, \frac{\partial m^{*}}{\partial h_{\xi_{2}}}<0$.

In a similar way,

$$
\begin{aligned}
\frac{\partial^{2} W}{\partial m \partial h_{\theta}} & =\frac{\partial^{2} C}{\partial m \partial h_{\theta}}=\frac{2 h_{\eta} m^{3}\left[h_{\eta}+m^{2}\left(h_{\theta}+h_{\xi_{1}}+2 h_{\xi_{1}} \alpha-3 h_{\xi_{1}} \alpha^{3}\right)\right]}{\left[m^{2} h_{\theta}+h_{\eta}+(1-\alpha) m^{2} h_{\xi_{1}}\right]^{4}}>0 ; \\
\frac{\partial^{2} W}{\partial m \partial h_{\xi_{1}}} & =\frac{\partial^{2} C}{\partial m \partial h_{\xi_{1}}}=\frac{2 h_{\eta} m^{3}(1-\alpha)^{2}\left[h_{\eta}+m^{2}\left(h_{\theta}+h_{\xi_{1}}+2 h_{\xi_{1}} \alpha\right)\right]}{\left[m^{2} h_{\theta}+h_{\eta}+(1-\alpha) m^{2} h_{\xi_{1}}\right]^{4}}>0 ;
\end{aligned}
$$

Lastly, to show the effect of $h_{\eta}$, notice that

$$
\begin{aligned}
\frac{\partial^{2} C}{\partial m \partial h_{\eta}} & =\frac{h_{\eta}^{2} m-2 h_{\eta} h_{\xi_{1}} m^{3} \alpha(1-\alpha)-m^{5}\left[h_{\theta}^{2}+h_{\xi_{1}}^{2}(1+2 \alpha)(1-\alpha)^{2}+2 h_{\theta} h_{\xi_{1}}\left(1-\alpha^{2}\right)\right]}{\left[m^{2} h_{\theta}+h_{\eta}+(1-\alpha) m^{2} h_{\xi_{1}}\right]^{4}} \\
& >\frac{m\left[h_{\eta}^{2}-2 h_{\eta} h_{\xi_{1}} \alpha(1-\alpha)-\left[h_{\theta}^{2}+h_{\xi_{1}}^{2}(1+2 \alpha)(1-\alpha)^{2}+2 h_{\theta} h_{\xi_{1}}\left(1-\alpha^{2}\right)\right]\right]}{\left[m^{2} h_{\theta}+h_{\eta}+(1-\alpha) m^{2} h_{\xi_{1}}\right]^{4}} \\
& \propto h_{\eta}^{2}-2 h_{\eta} h_{\xi_{1}} \alpha(1-\alpha)-\left[h_{\theta}^{2}+h_{\xi_{1}}^{2}(1+2 \alpha)(1-\alpha)^{2}+2 h_{\theta} h_{\xi_{1}}\left(1-\alpha^{2}\right)\right],
\end{aligned}
$$

where the second line uses $m<1$. Apparently, the last equation strictly increases in $h_{\eta}$. Since $h_{\eta}>3\left(h_{\theta}+h_{\xi_{1}}\right)>h_{\theta}+h_{\xi_{1}}$, we replace $h_{\eta}$ with $h_{\theta}+h_{\xi_{1}}$ and

$$
\begin{aligned}
& h_{\eta}^{2}-2 h_{\eta} h_{\xi_{1}} \alpha(1-\alpha)-\left[h_{\theta}^{2}+h_{\xi_{1}}^{2}(1+2 \alpha)(1-\alpha)^{2}+2 h_{\theta} h_{\xi_{1}}\left(1-\alpha^{2}\right)\right] \\
> & 4 \alpha h_{\xi_{1}}\left[2 h_{\theta}(2-\alpha)+h_{\xi_{1}}\left(4-\alpha-2 \alpha^{2}\right)\right]>0 .
\end{aligned}
$$

Therefore, $\frac{\partial^{2} W}{\partial m \partial h_{\eta}}=\frac{\partial^{2} C}{\partial m \partial h_{\eta}}>0$.

Taken together, we have $\frac{\partial m^{*}}{\partial h_{\theta}}>0, \frac{\partial m^{*}}{\partial h_{\xi_{1}}}>0, \frac{\partial m^{*}}{\partial h_{\eta}}>0$.

Proof. of Proposition 6: We solve the model using backward induction. First, we study the firm's investment strategy given his choice $n_{i}$ and other firms' choice $\hat{n}$. In particular, for any 
$n_{i}$ and $\hat{n}$, we can derive the expected payoff for firm $i$ as a function of $n_{i}$. Then, we examine the optimal choice, denoted as $n_{i}^{*}$, that maximizes the ex-ante expected payoff; that is, $n_{i}^{*}$ is the best response for firm $i$ given $\hat{n}$. Lastly, we impose the symmetric equilibrium condition, i.e., $n_{i}^{*}=\hat{n} \equiv n^{*}$.

Notice that for any $n_{i}$ and $\hat{n}$, because firm $i$ is infinitesimal, his report $r_{i}$ does not affect the average report $\bar{r}$. That is,

$$
\bar{r}=\theta+\hat{n} \eta
$$

which is a noisy signal of $\theta$ only. As we derived from our main model, firm $i$ 's investment is

$$
k_{i}=E_{i}\left[R_{i}\right]=E_{i}\left[(1-\alpha) \theta_{i}+\alpha K\right]
$$

where $\alpha \in[0,1)$. As a result, firm $i$ maximizes the ex-ante payoff at date 0 as follows

$$
\begin{gathered}
\max _{m_{i}} E_{\left\{\bar{r}, r_{i}, s_{i 1}, s_{i 2}\right\}}\left[R_{i} k_{i}-\frac{\left(k_{i}\right)^{2}}{2}\right] \\
\text { s.t. } k_{i}=E_{i}\left[(1-\alpha) \theta_{i}+\alpha K\right],
\end{gathered}
$$

where $E_{\left\{\bar{r}, r_{i}, s_{i 1}, s_{i 2}\right\}}[\cdot]$ means "taking expectation of $\left\{\bar{r}, r_{i}, s_{i 1}, s_{i 2}\right\}$ ".

The remaining proof proceeds as follows. In step 1, for benchmark case $(\alpha=0)$, we compare the privately optimal harmonization $n_{0}^{*}$ with the socially optimal harmonization $m_{0}^{*}$. In step 2 , for any $\alpha \in(0,1)$, we compare the privately optimal harmonization $n^{*}$ with the socially optimal harmonization $m^{*}$.

Step 1). When $\alpha=0, R_{i} k_{i}-\frac{\left(k_{i}\right)^{2}}{2}=\frac{\left(E_{i}\left[\theta_{i}\right]\right)^{2}}{2}=\frac{E_{i}\left[\theta_{i}^{2}\right]-\operatorname{Var}_{i}\left[\theta_{i}\right]}{2}$. Furthermore, by the law of iterative expectations, $E_{\left\{\bar{r}, r_{i}, s_{i 1}, s_{i 2}\right\}}\left[E_{i}\left[\theta_{i}^{2}\right]\right]=E\left[\theta_{i}^{2}\right]=\left(E\left[\theta_{i}\right]\right)^{2}+\operatorname{Var}\left(\theta_{i}\right)$ is a constant. Therefore,

$$
\max _{n_{i}} E_{\left\{\bar{r}, r_{i}, s_{i 1}, s_{i 2}\right\}}\left[R_{i} k_{i}-\frac{\left(k_{i}\right)^{2}}{2}\right] \Leftrightarrow \min _{n_{i}} \operatorname{Var}_{i}\left(\theta_{i}\right) .
$$

Notice that firm $i$ has four signals that are informative about $\theta_{i}: \bar{r}, r_{i}, s_{i 1}, s_{i 2}$. However, different from our main model, $\operatorname{Var}_{i}\left(\theta_{i}\right) \neq \operatorname{Var}_{i}(\theta)+\operatorname{Var}_{i}\left(\lambda_{i}\right)$. This is because for any arbitrary $n_{i} \neq \hat{n}, r_{i}$ contains incremental information for $\theta$ even conditional on $\bar{r}$. Therefore, we can compute $\operatorname{Var}_{i}\left(\theta_{i}\right)$ using the variance-covariance matrix of the multivariate normal 
distribution. For ease of exposition, we denote $\vec{I}=\left(\bar{r}, r_{i}, s_{i 1}, s_{i 2}\right)^{\prime}, \vec{E}_{I}=\left(\mu_{\theta}, \mu_{\theta}, \mu_{\theta}, 0\right)^{\prime}$, $\vec{V}=\left(\frac{1}{h_{\theta}}, \frac{1}{h_{\theta}}+\frac{1}{h_{\lambda}}, \frac{1}{h_{\theta}}, \frac{1}{h_{\lambda}}\right)$, and

$$
\Sigma=\left(\begin{array}{cccc}
\frac{1}{h_{\theta}}+\frac{\hat{n}^{2}}{h_{\eta}} & \frac{1}{h_{\theta}}+\frac{n_{i} \hat{n}}{h_{\eta}} & \frac{1}{h_{\theta}} & 0 \\
\frac{1}{h_{\theta}}+\frac{n_{i} \hat{n}}{h_{\eta}} & \frac{1}{h_{\theta}}+\frac{1}{h_{\lambda}}+\frac{n_{i}^{2}}{h_{\eta}}+\frac{\left(1-n_{i}\right)^{2}}{h_{\varepsilon}} & \frac{1}{h_{\theta}} & \frac{1}{h_{\lambda}} \\
\frac{1}{h_{\theta}} & \frac{1}{h_{\theta}} & \frac{1}{h_{\theta}}+\frac{1}{h_{\xi_{1}}} & 0 \\
0 & \frac{1}{h_{\lambda}} & 0 & \frac{1}{h_{\lambda}}+\frac{1}{h_{\xi_{2}}}
\end{array}\right) .
$$

Using the property of multivariate normal, we have

$$
\left(\begin{array}{c}
\theta_{i} \\
\vec{I}
\end{array}\right) \sim N\left(\left(\begin{array}{c}
\mu_{\theta} \\
\vec{E}_{I}
\end{array}\right),\left(\left(\begin{array}{cc}
\frac{1}{h_{\theta}}+\frac{1}{h_{\lambda}} & \vec{V} \\
\vec{V}^{\prime} & \Sigma
\end{array}\right)\right)\right)
$$

The conditional distribution satisfies

$$
\operatorname{Var}\left(\theta_{i} \mid \bar{r}, r_{i}, s_{i 1}, s_{i 2}\right)=\operatorname{Var}\left(\theta_{i}\right)-\vec{V} \Sigma^{-1} \vec{V}^{\prime}
$$

Take the first-order condition w.r.t. $n_{i}$, and it gives rise to firm $i$ 's the best response given $\hat{n}$ :

$$
\frac{\partial \operatorname{Var}\left(\theta_{i} \mid \bar{r}, r_{i}, s_{i 1}, s_{i 2}\right)}{\partial n_{i}}=0
$$

Now we impose the symmetric equilibrium condition, i.e., $n_{i}^{*}=\hat{n} \equiv n_{0}^{*}$, which yields the following implicit function

$$
n_{0}^{*}\left(h_{\lambda}\left(n_{0}^{*}-1\right)^{2}+h_{\varepsilon}+h_{\xi_{2}}\left(n_{0}^{*}-1\right)^{2}\right)=\left(1-n_{0}^{*}\right)\left(n_{0}^{*}\left(h_{\theta}+h_{\xi_{1}}\right)+h_{\eta}\right) .
$$

Recall that the socially optimal $m_{0}^{*}$ solves

$$
\frac{2 h_{\eta} m_{0}^{*}}{\left(\left(m_{0}^{*}\right)^{2}\left(h_{\theta}+h_{\xi_{1}}\right)+h_{\eta}\right)^{2}}-\frac{2 h_{\varepsilon}\left(1-m_{0}^{*}\right)}{\left(h_{\lambda}\left(m_{0}^{*}-1\right)^{2}+h_{\varepsilon}+h_{\xi_{2}}\left(m_{0}^{*}-1\right)^{2}\right)^{2}}=0
$$


Assumption 1 guarantees equation (19) is increases in $m_{0}^{*}$. Therefore,

$$
n_{0}^{*}>m_{0}^{*} \Leftrightarrow \frac{2 h_{\eta} n_{0}^{*}}{\left(\left(n_{0}^{*}\right)^{2}\left(h_{\theta}+h_{\xi_{1}}\right)+h_{\eta}\right)^{2}}-\frac{2 h_{\varepsilon}\left(1-n_{0}^{*}\right)}{\left(h_{\lambda}\left(n_{0}^{*}-1\right)^{2}+h_{\varepsilon}+h_{\xi_{2}}\left(n_{0}^{*}-1\right)^{2}\right)^{2}}>0 .
$$

Plugging equation (18), and the above condition can be further reduced to

$$
\begin{aligned}
& \frac{2 h_{\eta} n_{0}^{*}}{\left(\left(n_{0}^{*}\right)^{2}\left(h_{\theta}+h_{\xi_{1}}\right)+h_{\eta}\right)^{2}}-\frac{2 h_{\varepsilon}\left(1-n_{0}^{*}\right)}{\left(h_{\lambda}\left(n_{0}^{*}-1\right)^{2}+h_{\varepsilon}+h_{\xi_{2}}\left(n_{0}^{*}-1\right)^{2}\right)^{2}} \\
= & \frac{2 n_{0}^{*}}{\left(n_{0}^{*}\left(h_{\theta}+h_{\xi_{1}}\right)+h_{\eta}\right)^{2}}\left[h_{\eta}-\frac{h_{\varepsilon} n_{0}^{*}}{\left(1-n_{0}^{*}\right)}\right] .
\end{aligned}
$$

Therefore,

$$
n_{0}^{*}>m_{0}^{*} \Leftrightarrow h_{\eta}-\frac{h_{\varepsilon} n_{0}^{*}}{\left(1-n_{0}^{*}\right)}>0 \Leftrightarrow n_{0}^{*}<\frac{h_{\eta}}{h_{\eta}+h_{\varepsilon}} .
$$

Rearrange equation (18) results in $n_{0}^{*}$ being a solution to the following polynomial function of $x$ :

$G(x)=-h_{\eta}+\left(h_{\lambda}+h_{\eta}+h_{\varepsilon}+h_{\xi_{2}}\right) x-\left(h_{\theta}+2 h_{\lambda}+h_{\xi_{1}}+2 h_{\xi_{2}}\right) x^{2}+\left(h_{\theta}+h_{\lambda}+h_{\xi_{1}}+h_{\xi_{2}}\right) x^{3}$.

It is easy to verify that $G^{\prime}(x)>0$. Therefore,

$$
\begin{aligned}
n_{0}^{*} & <\frac{h_{\eta}}{h_{\eta}+h_{\varepsilon}} \Leftrightarrow G\left(n_{0}^{*}\right)<G\left(\frac{h_{\eta}}{h_{\eta}+h_{\varepsilon}}\right) \\
& \Leftrightarrow h_{\varepsilon}\left(h_{\lambda}+h_{\xi_{2}}\right)>h_{\eta}\left(h_{\theta}+h_{\xi_{1}}\right) .
\end{aligned}
$$

That is, $n_{0}^{*}>m_{0}^{*}$ if and only if $h_{\varepsilon}\left(h_{\lambda}+h_{\xi_{2}}\right)>h_{\eta}\left(h_{\theta}+h_{\xi_{1}}\right)$.

Step 2) The analysis when $\alpha>0$ is similar to that in step 1, and thus we omit some tedious algebra for brevity. Given the information set for firm $i$, as we derived in our main model, firm $i$ will invest

$$
k_{i}=(1-\alpha) E_{i}\left[\theta_{i}\right]+\alpha E_{i}[K]
$$

Notice that, since all other firms choose $\hat{n}$, firm $j$ 's investment $k_{j}$ will be based on its report $r_{j}$, the aggregate report $\bar{r}$ and the private signals. In addition, because firm $i$ is infinitesimal, the aggregate investment $K$ will not be affected by its investment $k_{i}$. It means, for firm $j \neq i$, 
its forecasts on the fundamental $\theta_{j}$ and total investment $K$ remain the same as in our main model, and therefore the equilibrium aggregate investment is

$$
K=\int_{0}^{1} k_{j} d j=\frac{h_{\theta} \mu_{\theta}+\frac{h_{\eta}}{\hat{n}^{2}} \bar{r}+(1-\alpha) h_{\xi_{1}} \theta}{h_{\theta}+\frac{h_{\eta}}{\hat{n}^{2}}+(1-\alpha) h_{\xi_{1}}}
$$

Firm $i$ rationally anticipates how $K$ is formed in equilibrium, and thus the ex-ante payoff for firm $i$ is

$$
E\left[V_{i}\right]=\frac{1}{2}\left\{(1-\alpha)\left(E_{i}\left[\lambda_{i}\right]+E_{i}[\theta]\right)+\alpha \frac{h_{\theta} \mu_{\theta}+\frac{h_{\eta}}{\hat{n}^{2}} \bar{r}+(1-\alpha) h_{\xi_{1}} E_{i}[\theta]}{h_{\theta}+\frac{h_{\eta}}{\hat{n}^{2}}+(1-\alpha) h_{\xi_{1}}}\right\}^{2}
$$

For any $n_{i}, E_{i}[\theta]$ and $E_{i}\left[\lambda_{i}\right]$ can be derived as follows. Denote $\vec{V}_{1}=\left(0, \frac{1}{h_{\lambda}}, 0, \frac{1}{h_{\lambda}}\right), \vec{V}_{2}=$ $\left(\frac{1}{h_{\theta}}, \frac{1}{h_{\theta}}, \frac{1}{h_{\theta}}, 0\right), \vec{S}=\left(\bar{r}, r_{i}, s_{i 1}, s_{i 2}\right)^{-1}$ and $\vec{\mu}=E[\vec{S}]=\left(\mu_{\theta}, \mu_{\theta}, \mu_{\theta}, 0\right)^{-1}$, then

$$
\begin{aligned}
E_{i}\left[\lambda_{i}\right] & =\vec{V}_{1} \Sigma^{-1}(\vec{S}-\vec{\mu}) \\
E_{i}[\theta] & =\mu_{\theta}+\vec{V}_{2} \Sigma^{-1}(\vec{S}-\vec{\mu}) .
\end{aligned}
$$

Substitute the conditional expectation $E_{i}\left[\lambda_{i}\right]$ and $E_{i}[\theta]$ in equation (20), the ex-ante payoff is

$$
E\left[V_{i}\right]=E_{\left\{\bar{r}, r_{i}, s_{i 1}, s_{i 2}\right\}}\left[R_{i} k_{i}-\frac{k_{i}^{2}}{2}\right]
$$

Take the first-order condition w.r.t. $n_{i}$, and it yields the first best response for firm $i$, denoted as $n_{i}^{*}$. Impose the symmetry condition, i.e., $n_{i}^{*}=\hat{n} \equiv n^{*}$, and thus the equilibrium $n^{*}$ is a solution to the following condition.

$$
\left.\frac{\partial E\left[V_{i}\right]}{\partial n_{i}}\right|_{n_{i}=\hat{n} \equiv n^{*}}=0
$$

Now we can compare $n^{*}$ and $m^{*}$. For ease of exposition, we rewrite the equation of $n^{*}$ and $m^{*}$ as a function of $x$. Specifically, we replace $n^{*}$ with $x$ in equation $\left.\frac{\partial E\left[V_{i}\right]}{\partial n}\right|_{n_{i}=\hat{n} \equiv n^{*}}=0$, and define the function as $R(x)$; replace $m^{*}$ with $x$ in equation $\left.\frac{\partial W}{\partial m}\right|_{m=m^{*}}=0$, and define it 
as $T(x)$. After some tedious algebra, we can show that

$$
T(x)-R(x) \propto(2 \alpha-1) h_{\eta}\left(h_{\lambda}+h_{\xi_{2}}\right)(1-x)^{2}+\underbrace{\alpha^{2} h_{\eta} h_{\varepsilon}+(1-\alpha)^{2} h_{\varepsilon} x^{2}\left(h_{\theta}-\alpha h_{\xi_{1}}+h_{\xi_{1}}\right.}_{+}) .
$$

Apparently, as long as $\alpha>\frac{1}{2}, T(x)-R(x)>0$ for any $x \in(0,1)$, and hence $T\left(n^{*}\right)>$ $R\left(n^{*}\right)=0$. On the other hand, recall that assumption 1 guarantee the concavity of the welfare function $W$, i.e., $T^{\prime}(x)<0$. In other words, for any $x \in(0,1), x<m^{*}$ if and only if $T(x)>T\left(m^{*}\right)=0$. Therefore, given $\alpha>\frac{1}{2}, T\left(n^{*}\right)>0$ and consequently $n^{*}<m^{*}$ always holds. 


\section{Appendix II: Mirco-foundation of the Investment Game}

In our main model, we assume that each firm's return to investment is a linear combination of its fundamental and other firms' behavior. In this section, we provide a micro-foundation of the payoff structure (1). Similar formulations have been commonly used in the economics literature (see, e.g., Angeletos and La'O (2013)).

Consider a two-date model with a manufacturing country that produces final consumption goods and a continuum of supplier countries $i \in[0,1]$ that supply intermediate capital goods to the manufacturing country. Each country has a risk-neutral representative consumer and a representative firm. The consumer in the manufacturing country has no initial wealth but owns the firm and its production technology. Each consumer in the supplier countries is endowed with a unit of consumption goods. At date 1, each consumer chooses the amount of consumption at $t=1$, denoted by $c_{i}$, and the amount of investment in the firm of the consumer's country, denoted by $x_{i}$ (but not in the firm of other countries due to a home bias). That is, $c_{i}=1-x_{i}$. Investment of $x_{i}$ generates $x_{i}$ units of intermediate goods, which the manufacturing-country firm thereafter acquires and uses jointly with the intermediate goods from other countries to produce consumption goods at $t=2$. The production technology of the manufacturing country is given by

$$
Q=A X^{\eta}
$$

where

$$
X=\left(\int_{0}^{1} x_{i}^{1-\rho} d i\right)^{\frac{1}{1-\rho}} .
$$

Each supplier-country firm receives a price $p_{i}$ for each unit of its intermediate goods contribution such that the revenue for each firm is $p_{i} x_{i}$. We assume that the net profit margin for each firm is $\Theta_{i}$ such that each firm generates a net profit of $\Theta_{i} p_{i} x_{i}$, which equals the firm revenue minus the operating cost. Since the consumer is the only investor of the firm, the consumer obtains all the profits from the firm's production. We assume that the profit margin $\Theta_{i}>0$ follows a log-normal distribution with mean $\bar{\Theta}$. For simplicity, we further as-

sume that the mean $\bar{\Theta}$ is sufficiently small such that the probability that $\Theta_{i}>1$ is negligible. 
Before the consumer makes the investment decision, the firm's accounting system provides (noisy) estimates about $\Theta_{i}$ to the consumer at $t=1$. We do not consider any agency conflict between the firm and the consumer such that the firm operates to maximize the consumer's welfare.

We solve the model by backward induction. At $t=2$, the manufacturing-country firm chooses its demand for the intermediate goods $x_{i}$ to maximize its profit:

$$
\max _{x_{i}} \pi=Q-\int_{0}^{1} p_{i} x_{i} d i
$$

Taking the first-order condition regarding $x_{i}$ gives that:

$$
\begin{aligned}
\frac{\partial \pi}{\partial x_{i}} & =\frac{\partial Q}{\partial x_{i}}-p_{i} \\
& =A \eta X^{\eta-1} \frac{\partial X}{\partial x_{i}}-p_{i} \\
& =A \eta X^{\eta-1} \frac{1}{1-\rho}\left(\int_{0}^{1} x_{i}^{1-\rho} d i\right)^{\frac{\rho}{1-\rho}}(1-\rho)\left(x_{i}\right)^{-\rho}-p_{i} \\
& =A \eta X^{\eta-1} X^{\rho} x_{i}^{-\rho}-p_{i} .
\end{aligned}
$$

Therefore,

$$
p_{i}=A \eta X^{\rho+\eta-1} x_{i}^{-\rho} .
$$

Equation (21) characterizes, at a given price $p_{i}$, the manufacturing-country firm's demand for the intermediate goods from a supplier-country firm $i, x_{i}$.

At $t=1$, each supplier-country consumer chooses its supply of intermediate goods to maximize the utility:

$$
\max _{x_{i}} E_{i}\left[1-x_{i}+\Theta_{i} p_{i} x_{i}\right]
$$

subject to the demand curve (21). Plugging (21) into the objective function results in:

$$
\max _{x_{i}} 1-x_{i}+A \eta x_{i}^{1-\rho} E_{i}\left[\Theta_{i} X^{\rho+\eta-1}\right]
$$


Taking the first-order condition results in

$$
x_{i}^{\rho}=A \eta(1-\rho) E_{i}\left[\Theta_{i} X^{\rho+\eta-1}\right] .
$$

A log-linear approximation around $\Theta_{i}=\bar{\Theta}$ results in

$$
\log x_{i}-\log \bar{X}=\left(1-\frac{1-\eta}{\rho}\right) E_{i}[\log X-\log \bar{X}]+\frac{1}{\rho} E_{i}\left[\log \Theta_{i}-\log \bar{\Theta}\right]
$$

where $\bar{X}$ denotes the value of $x_{i}$ at $\Theta_{i}=\bar{\Theta}$. In addition, a log-linear approximation of $X$ around $\Theta_{i}=\bar{\Theta}$ gives that

$$
\log X-\log \bar{X}=\int_{0}^{1}\left[\log x_{i}-\log \bar{X}\right] d i
$$

Thus we obtain that

$$
\log x_{i}-\log \bar{X}=\left(1-\frac{1-\eta}{\rho}\right) E_{i}\left[\int_{0}^{1}\left[\log x_{i}-\log \bar{X}\right] d i\right]+\frac{1}{\rho} E_{i}\left[\log \Theta_{i}-\log \bar{\Theta}\right]
$$

Define that

$$
\begin{aligned}
k_{i} & \equiv\left(1+\frac{\eta}{\rho}\right)\left[\log x_{i}-\log \bar{X}\right] \\
K & =\int_{0}^{1} k_{i} d i=\left(1+\frac{\eta}{\rho}\right) \int_{0}^{1}\left[\log x_{i}-\log \bar{X}\right] d i \\
\theta_{i} & \equiv\left(1+\frac{\eta}{\rho}\right)\left[\log \Theta_{i}-\log \bar{\Theta}\right] \\
\alpha & \equiv \frac{1-\frac{1-\eta}{\rho}}{1+\frac{\eta}{\rho}}
\end{aligned}
$$

Note that, given that $\Theta_{i}$ follows a log-normal distribution, $\theta_{i}$ follows a normal distribution. Thus (22) becomes:

$$
k_{i}=(1-\alpha) E_{i}\left[\theta_{i}\right]+\alpha E_{i}[K]
$$

which has the same linear functional form as (1) assumed in our main model. 


\section{References}

Anat R Admati and Paul Pfleiderer. Forcing firms to talk: Financial disclosure regulation and externalities. The Review of financial studies, 13(3):479-519, 2000.

George-Marios Angeletos and Jennifer La'O. Sentiments. Econometrica, 81(2):739-779, 2013.

G.M. Angeletos and A. Pavan. Transparency of information and coordination in economies with investment complementarities. American Economic Review, 94(2):91-98, 2004.

G. Angeletos and A. Pavan. Efficient use of information and social value of information. Econometrica, 75(4):1103-1142, 2007.

A. Arya and B. Mittendorf. On the synergy between disclosure and investment beauty contests. Journal of Accounting and Economics, 61(2):255-273, 2016.

C Richard Baker and Elena M Barbu. Trends in research on international accounting harmonization. The International Journal of Accounting, 42(3):272-304, 2007.

Ray Ball and Gil Sadka. Aggregate earnings and why they matter. Journal of Accounting Literature, 34:39-57, 2015.

R. Ball, S.P. Kothari, and A. Robin. The effect of international institutional factors on properties of accounting earnings. Journal of Accounting and Economics, 29(1):1-51, 2000.

R. Ball, A. Robin, and J.S. Wu. Incentives versus standards: properties of accounting income in four east asian countries. Journal of Accounting and Economics, 36(1):235-270, 2003.

M.E. Barth, G. Clinch, and T. Shibano. International accounting harmonization and global equity markets. Journal of Accounting and Economics, 26(1):201-235, 1999.

Mark T Bradshaw, Brian J Bushee, and Gregory S Miller. Accounting choice, home bias, and us investment in non-us firms. Journal of Accounting Research, 42(5):795-841, 2004.

Ulf Brüggemann, Jörg-Markus Hitz, and Thorsten Sellhorn. Intended and unintended consequences of mandatory ifrs adoption: A review of extant evidence and suggestions for future research. European Accounting Review, 22(1):1-37, 2013. 
R.M. Bushman and J.D. Piotroski. Financial reporting incentives for conservative accounting: The influence of legal and political institutions. Journal of Accounting and Economics, 42(1):107-148, 2006.

Q. Chen, I. Goldstein, and W. Jiang. Payoff complementarities and financial fragility: Evidence from mutual fund outflows. Journal of Financial Economics, 97(2):239-262, 2010.

Chen Chen, Danqing Young, and Zili Zhuang. Externalities of mandatory ifrs adoption: Evidence from cross-border spillover effects of financial information on investment efficiency. The Accounting Review, 88(3):881-914, 2013.

Q Chen, T.R. Lewis, K. Schipper, and Y. Zhang. Uniform versus discretionary regimes in reporting information with unverifiable precision and a coordination role. Journal of Accounting Research, 55(1):153-196, 2017.

H.B. Christensen, L. Hail, and C. Leuz. Mandatory IFRS reporting and changes in enforcement. Journal of Accounting and Economics, 56(2):147-177, 2013.

H.B. Christensen, L. Hail, and C. Leuz. Capital-market effects of securities regulation: Prior conditions, implementation, and enforcement. The Review of Financial Studies, 29(11):2885-2924, 2016.

Vicentiu M Covrig, Mark L Defond, and Mingyi Hung. Home bias, foreign mutual fund holdings, and the voluntary adoption of international accounting standards. Journal of accounting research, 45(1):41-70, 2007.

H. Daske, L. Hail, C. Leuz, and R. Verdi. Mandatory ifrs reporting around the world: Early evidence on the economic consequences. Journal of accounting research, 46(5):1085-1142, 2008.

Holger Daske, Luzi Hail, Christian Leuz, and Rodrigo Verdi. Adopting a label: Heterogeneity in the economic consequences around ias/ifrs adoptions. Journal of Accounting Research, 51(3):495-547, 2013.

E.T. De George, X. Li, and L. Shivakumar. A review of the IFRS adoption literature. Review of Accounting Studies, 21(3):898-1004, 2016. 
Mark DeFond, Xuesong Hu, Mingyi Hung, and Siqi Li. The impact of mandatory ifrs adoption on foreign mutual fund ownership: The role of comparability. Journal of accounting and economics, 51(3):240-258, 2011.

R. Dye and S. Sridhar. A positive theory of flexibility in accounting standards. Journal of Accounting and Economics, 46(2):312-333, 2008.

Vivian W Fang, Michael Iselin, and Gaoqing Zhang. Financial statement comparability: Theory and evidence. Available at SSRN 2858301, 2019.

M.J. Fishman and K.M. Hagerty. Disclosure decisions by firms and the competition for price efficiency. The Journal of Finance, 44(3):633-646, 1989.

P. Gao and X. Jiang. Reporting choices in the shadow of bank runs. Journal of Accounting and Economics, 65(1):85-108, 2018.

Pingyang Gao, Xu Jiang, and Gaoqing Zhang. Firm value and market liquidity around the adoption of common accounting standards. Journal of Accounting and Economics, 68(1):101220, 2019.

Frank Gigler, Chandra Kanodia, and Raghu Venugopalan. Mark-to-market: Real effects and social welfare, 2016.

I. Goldstein and A. Pauzner. Demand-deposit contracts and the probability of bank runs. Journal of Finance, 60(3):1293-1327, 2005.

L. Hail, C. Leuz, and P.D. Wysocki. Global accounting convergence and the potential adoption of IFRS by the US (Part I): Conceptual underpinnings and economic analysis. $A c$ counting Horizons, 24(3):355-394, 2010.

L. Hail, C. Leuz, and P.D. Wysocki. Global accounting convergence and the potential adoption of IFRS by the US (Part II): Political factors and future scenarios for US accounting standards. Accounting Horizons, 24(4):567-588, 2010.

Amy P Hutton, Lian Fen Lee, and Susan Z Shu. Do managers always know better? the 
relative accuracy of management and analyst forecasts. Journal of Accounting Research, 50(5):1217-1244, 2012.

Mark Lang, Jana Smith Raedy, and Wendy Wilson. Earnings management and cross listing: Are reconciled earnings comparable to us earnings? Journal of accounting and economics, 42(1-2):255-283, 2006.

C. Leuz and R.E. Verrecchia. The economic consequences of increased disclosure. Journal of Accounting Research, 38(supplement):91-124, 2000.

C. Leuz and P.D. Wysocki. The economics of disclosure and financial reporting regulation: Evidence and suggestions for future research. Journal of Accounting Research, 54(2):525$622,2016$.

C. Leuz, D. Nanda, and P.D. Wysocki. Earnings management and investor protection: an international comparison. Journal of Financial Economics, 69(3):505-527, 2003.

C. Leuz. IAS versus US GAAP: information asymmetry-based evidence from Germany's new market. Journal of accounting research, 41(3):445-472, 2003.

Siqi Li. Does mandatory adoption of international financial reporting standards in the european union reduce the cost of equity capital? The accounting review, 85(2):607-636, 2010.

Feng Li. Earnings quality based on corporate investment decisions. Journal of Accounting Research, 49(3):721-752, 2011.

Pierre Jinghong Liang and Gaoqing Zhang. On the social value of accounting objectivity in financial stability. The Accounting Review, 94(1):229-248, 2019.

S. Morris and H.S. Shin. Social value of public information. The American Economic Review, 92(5):1521-1534, 2002.

David P Myatt and Chris Wallace. Endogenous information acquisition in coordination games. The Review of Economic Studies, 79(1):340-374, 2012. 
Joseph D Piotroski and Darren T Roulstone. The influence of analysts, institutional investors, and insiders on the incorporation of market, industry, and firm-specific information into stock prices. The accounting review, 79(4):1119-1151, 2004.

G. Plantin, H. Sapra, and H.S. Shin. Marking-to-market: Panacea or Pandora's Box? Journal of Accounting Research, 46(2):435-460, 2008.

Korok Ray. One size fits all? costs and benefits of uniform accounting standards. Journal of International Accounting Research, 17(1):1-23, 2018.

Sugata Roychowdhury, Nemit Shroff, and Rodrigo S Verdi. The effects of financial reporting and disclosure on corporate investment: A review. Journal of Accounting and Economics, 68(2-3):101246, 2019.

Securities and Exchange Commission. Roadmap for the potential use of financial statements prepared in accordance with international financial reporting standards by us issuers. 2008 .

D Tweedie. Prepared statement of sir david tweedie, chairman of iasb to officials of the singaporean government, 2008.

Mariana Vijil. Aid for trade effectiveness: Complementarities with economic integration. The World Economy, 37(4):555-566, 2014.

Clare Wang. Accounting standards harmonization and financial statement comparability: Evidence from transnational information transfer. Journal of Accounting Research, 52(4):955$992,2014$.

Sang Wu and Wenjie Xue. Optimal comparability, real effects, and asset prices. Real Effects, and Asset Prices (June 24, 2019), 2019.

Gaoqing Zhang. Competition and opacity in the financial system. Management Science, Forthcoming. 